Article

\title{
Indirect Effects, Biotic Inferential Interactions and Time Functions in H-Semiotic Systems: Ecosystems Case
}

\author{
José-Luis Usó-Doménech ${ }^{1}$, Josué-Antonio Nescolarde-Selva ${ }^{1, * \mathbb{C}}$, Miguel Lloret-Climent ${ }^{1}$, \\ Hugh Gash ${ }^{2}$ and Kristian Alonso-Stenberg ${ }^{1}$ (D) \\ 1 Department of Applied Mathematics, University of Alicante, 03690 Alicante, Spain; \\ joseluisusodomenech@gmail.com (J.-L.U.-D.); miguel.lloret@ua.es (M.L.-C.); kristian.alonso@ua.es (K.A.-S.) \\ 2 Institute of Education, Dublin City University, D09 Y18 Dublin, Ireland; hugh.gash@spd.dcu.ie \\ * Correspondence: josue.selva@ua.es; Tel.: 0034-680-418-381; Fax: 0034-965-909-707
}

Received: 15 January 2019; Accepted: 28 March 2019; Published: 31 March 2019

check for updates

\begin{abstract}
The main objectives of this paper are to formulate an introduction to the mathematical theory of indirect effects with respect to some biotic relations, including symbiosis, commensalism, mutualism and predation, along with the time functions for these relationships. We employ the theory of system linkage in Patten's Theory of Environment to develop an analysis of the theoretical properties of direct and indirect influences, using the variables and structure of each system involved in the linkage. In this paper, in order to formulate the mathematical theory, we develop, as a contribution to Patten's Theory of Environment, so-called $H$-semiotic systems.
\end{abstract}

Keywords: ecological system; ecosystem; network; structural function; systems

\section{Introduction}

Each ontological entity is physically a system of elementary particles (quarks and leptons), and binding forces, and it is both open to energy (non-isolated), and open to matter situated within the continuum of the universe. Each ontological entity changes and evolves in spacetime by lawfully mapping stimuli that include afferent or external determinants, states or internal determinants, and subsequent states and responses or efferent behaviors [1]. Stimuli can be divided into two classes, and by means of these classes, agents (an agent being anything non-living or living) can be distinguished: A non-living system or object is anything that only responds to a physical or ontological stimulus, whereas a living system or subject is anything that responds to a physical stimulus, as well as to an epistemic, phenomenological or semiotic stimulus. Two kinds of lawful determination emerge from agent interactions: Causal determination, taking place in physical reality, and inferential determination, occuring in phenomenological reality. There are two kinds of causal interactions: Transactions, involving direct exchange of matter or energy between two agents, and relations, involving indirect consequences of these transactions. Inferential interactions are relational, and always have a transactional basis. Inferential interactions between two or more subjects are biotic inferential interactions, or biotic relations.

Sets of interacting ontological agents comprise networks, which can be explicit and ontological, but are more usually implicit and immanent, arising de facto from the causal or inferential interactions between agents. Delimiting interactive networks in time, space, or both, produces subnetworks or systems. The boundaries of systems can be either ontological or immanent (semiotic). Causal or inferential determination between ontological agents or groups of agents within a bounded network or system can be direct or local, indirect or global, or a combination of both.

Each ontological entity is itself a system, a bounded network of other ontological agents of a lower scale that interact within the confines of a defined system. 
An ontologic system [2,3] $(M, R)$ is an oriented, causal, functional system composed of a set $M$ whose elements are agents (objects and/or subjects), defined as time functions on a set $T$, and a relational set $R=\left\{R_{T}, R_{R}\right\}$ of binary relations on $M \times M$ manifested by physical forces and/or energy exchange exerted between pairs of agents. A binary transaction $R_{T}$ is the direct exchange of matter or energy between two agents. A binary relation $R_{R}$ is the indirect consequence of a binary transaction that applies to the same two or other agents, two at a time. Transactions are "real" or ontic categories; relations are "virtual" or epistemic and implicit. In this formulation, transactions have priority because they involve physical transfers of energy or matter without which relations could not occur. However, given any established ontic domain, relations can be prior, as they can initiate transactions.

An ontologic (or ontological) system is one that is conceived by a subject, and is responsive to methodological requirements: To describe and circumscribe the agent in terms of its origin and its history as an epistemological principle. i.e., the system involves the whole, that is, the principle by all observed phenomena constituting a set full of meanings, and which it is impossible to understand outside of that specific context. An ontological system is not a classification of elements ordered according to the code of values of the subject. Nor is it a classification resulting from the quantification of phenomena, nor an array whose elements function as a living organism, nor is it a system of elements. It is a system of transactions and relationships between elements directed towards achieving specific effects, i.e., the system's function. To define a structural system consists then in the discovery of its role, and in making an inventory of elements whose interrelations appear relevant to the performance of that function. The relevant elements are exclusively phenomena that have meaning within the system. To establish what is relevant, and what is not, one must undertake a thorough analysis of all elements from the dual perspective of considering each element both in itself, and in its relationship to the whole.

A concept is a type of mental internal structure characterized by having control over [4] system responses (behaviors) and semantic content. A system has concepts, and its internal states perform a game and a kind of coordination between stimuli and responses that do not themselves determine the system. The concepts that determine the system depend on the type of information that the subject has acquired.

However, it does not matter that the concept is something determined by its semantic properties. This is why concepts are holons, as they meet the condition of a structure which has two faces: One looking inward toward its information sources, and the other looking out, i.e., to its effects and consequences. No structure exists unless you have both, but what gives a structure its conceptual identity is its etiologic specificity. The concept of Ontological System (Reality) raises semiotic issues. By what right do we affirm that reality is a system? On what scientific data is the system based? Systems begin with, are founded on, and are determined by, our knowledge: Reality is systemic when we know it, and because we know it. Since knowledge imposes its conditions, whatever has a systemic nature will be the result of knowledge itself. As David Hume (1711-1776) [5] says, there is nothing in our experience specifying "cause". This causal relationship is due to a rational activity establishing a link between two events. In general, all types of relationships are not themselves objects of our direct experience. But if relations are essential elements of systems, we must conclude that they are mental constructs, and therefore we conclude that systems begin with knowledge. The systemic structures that are our models of reality are the fruits of reason. Our own knowledge of an object is a system, and so are the concepts from the system of all the perceptions or properties identified in these perceptions. In the concepts of things, we see similarities and differences. If we come together based on similarities, and we divide in relation to differences, we classify in terms of classes. This translates into natural language in the form of nouns, adjectives and intransitive verbs. One can imagine an integrative meta-language which would integrate all languages. In this case, a General Systems Theory should be something similar to Chomsky's universal grammar, that is, an abstract theory of languages - namely - a mathematical form (a particular case of a semiotic system) of the concept of a system. 
An $H$-semiotic system, $H$-system, or just $H[2,3,6-8]$ is one whose object set $M$ is ontic, but with a relational set, $R_{I}$ is formed by "inferential interactions" [9]. An Inferential interaction $R_{I} \subset\left\{R_{T}, R_{R}\right\}$ is a relation whose significance is informational, transcending the material and physical forces upon which they depend. An inferential interaction involves signal flows and ontic signs, which take semantic meaning within epistemological frames that are established between interactive pairs from $M$. $H$-systems that are oriented as causal, functional systems are defined by an external observer whose object set $M$ responds to information.

Structural analysis of a phenomenological field consists in the demonstration that there is a structure (the ontological system), the explanatory principle of which is based on the underlying configuration that defines it in its singularity and its variability. This configuration does not belong to the field of events that can be perceived directly by observers, although the perception through them will be either direct or indirect, and while it obscures the consciousness that the subject has about the system, it is "modeled" through the observer's analysis. This default configuration is the structure of the system. In a traditional sense, the term structure evokes the idea of relationships between elements and between parts of the whole. If we assume these relationships, we are considering as a backdrop or context that it implies a fundamental organization of the object, permitting a distinction between what is essential, and what is an accessory of an observable organization. The structure is, therefore, an empirical fact. Another consequence that we can establish is that it allows comparisons to be made. Being synonymous with "context", it is possible to represent it abstractly and to identify it with other wholes. It is a matter, therefore, of comparing like with like, and allowing the establishment of a topology of structures based on the identity of the $H$-systems. Between systematized sets, the similarity or likeness can be observed. That is, the structure is both a configuration of what is real (the Ontological System), and a law by comparing multiple structures.

Although in the study of ecosystems the relationships between the variables can be measured, and the effects, direct and indirect, can be compared between different species, as in the case of relations of predation and competition [10,11], there has not been a profound development in the broader context of General Systems Theory. The problems to be solved by this Theory include the question of quantifying the relationships between variables (objects or attributes) of a system, or in the more general case of a system with its subsystems, or of a multilevel system [12]. This paper aims to make a first step towards formalizing and analyzing the basic concepts and theoretical properties of influences from a viewpoint of the variables and the structure of ecosystems. We do this in accordance with Patten's Theory of Environment. The application of structural functions to specific cases is beyond the scope of this paper. These are structures that are not linguistic and belong to ontological reality, and have been related with $H$-systems or semiotic systems, which if they were linguistic would belong to the epistemology of the human species. There is only one exception: Those structures in which the object set $M$ is entirely or partially made up by expressions such that the structure always has a certain linguistic quality. In that case, a special character is attributed to these relevant systems, and in logical-mathematical terminology are said to be couched in a "second level" language, or a "metalanguage" These structures are linguistic wholly or partly, and are related with metalinguistic systems. Returning to structures that are not linguistic agents, and do not differ fundamentally from those which have been discussed in the preceding paragraph, we may wonder whether they constitute reality, which we have defined as the ontological system. Will they constitute, at least in part, the objective world? We think the answer may be no, but the whole issue is extremely complex. Ultimately, we can say that the structures should be seen as mental constructions made by the subject, and in our case, as a result of human rational activity, and a reflection on certain aspects of experience.

The remaining parts of the paper are organized as follows: Section 2 provides the systemic concepts: Interposed set, stimulus-response process, state transition, internal transition process, internal response process, process space and internal process space. Section 3 focuses on ecosystems, and direct and indirect effects. Section 4 discusses time-forward and time-backward time functions, as well as four 
theorems. In Section 5 we connect biotic relations with time functions. Finally, in Section 6, we present our conclusions.

\section{Systemic Concepts}

We need now to provide the systemic concepts: Interposed set, stimulus-response process, state transition, internal transition process, internal response process, process space and internal process space in order to formalize the mathematical theory of indirect effects. Ecosystems are networks of interacting ontological agents.

In biomathematics, Rosen [13-15] is known for his original work on a class of relational models of living organisms, called $(M, R)$-systems. A system $\Sigma=(M, R)$ is a set $M$ of objects (living organisms), and a set $R$ composed of binary transactions or relations between these [16-21]. Let:

$$
R \subset P(M \times M)=P\left(M^{2}\right) ; \forall r \in R, r \subset M \times M,
$$

where $P$ denotes the power set, and $r=\left\{\left(x_{i}, y_{j}\right) \mid x_{i} \in M, y_{j} \in M\right\}$.

A time set $T$ is a linearly ordered set whose order is expressed by $\leq$. Let $\Theta$ and $\Xi$ be two sets and $T$ a time set. Let $\Theta^{T}$ and $\Xi^{T}$ be the set of all the functions of $T$ in $\Theta$ and $\Xi$ respectively, i.e., $\Theta^{T}=\{\rho: T \rightarrow \Theta\}, \Xi^{T}=\{\xi: T \rightarrow \Xi\}$. Let $Z$ and $Y$ be two sets such that $Z \subset \Theta^{T}, Y \subset \Xi^{T}$. In a system $\sum_{t}, t$ is the time between the stimulus and response representing a relationship $R_{i}, i=1,2$ between the sets $Z$ and $Y$. Let $\left[t_{0}, t\right] \subset T$, with $t>t_{0}$ be a time subset, when the following condition is satisfied:

$$
\Sigma\left[t_{0}, t\right] \subset Z\left[t_{0}, t\right] \times Y\left[t_{0}, t\right]
$$

A set $L\left[t_{0}, t\right]$ is interposed between the sets $Z\left[t_{0}, t\right]$ and $Y\left[t_{0}, t\right]$, if there exists a set $\Lambda^{T}=\{\lambda: T \rightarrow \Lambda\}$ such that $L\left[t_{0}, t\right] \subset \Lambda^{T}$ and $\exists R_{1} \subset Z\left[t_{0}, t\right] \times L\left[t_{0}, t\right]$ and $\exists R_{2} \subset L\left[t_{0}, t\right] \times Y\left[t_{0}, t\right]$.

Definition 1. (interposed set) Assuming $Z\left[t_{0}, t\right], L\left[t_{0}, t\right]$ and $Y\left[t_{0}, t\right]$ are sets of the time functions on $\left[t_{0}, t\right]$ with images in $M$. Let $R_{1} \subset Z\left[t_{0}, t\right] \times L\left[t_{0}, t\right]$ and $R_{2} \subset L\left[t_{0}, t\right] \times Y\left[t_{0}, t\right]$. We define the set $S\left[t_{0}, t\right]$ of states of the system $\Sigma$ as the interposed set between sets $Z\left[t_{0}, t\right]$ and $Y\left[t_{0}, t\right]$ and then the following holds

$$
\forall\left(z\left[t_{0}, t\right], y\left[t_{0}, t\right]\right) \in R_{i}, i=1,2, \exists s_{1}\left[t_{0}, t\right] \in S\left[t_{0}, t\right] \mid\left(z\left[t_{0}, t\right], s_{1}\left[t_{0}, t\right]\right) \in R_{1} \wedge\left(s_{1}\left[t_{0}, t\right], y\left[t_{0}, t\right]\right) \in R_{2} .
$$

Any set of time functions can be interpreted as a behavioral set, since it follows the behavior of elements of $M$ in time, representing the families of all the possible trajectories (behavioral paths); $z\left[t_{0}, t\right], s\left[t_{0}, t\right], y\left[t_{0}, t\right]$ are specific trajectories [22].

The state space $S^{S}$ of a system $\Sigma[23-25]$ is the Cartesian product of all the states $s_{i} \in S$, then using the restriction of the domain to $\left[t_{0}, t\right]$, we obtain:

$$
S^{s}\left[t_{0}, t\right]=\stackrel{n}{X}_{i=1}^{n} s_{i}\left[t_{0}, t\right]
$$

The state space consists of state trajectories only, and is defined by the categories of objects $M$ and relations $R$ by which the observer conceives the system $\Sigma$.

Let $\Sigma\left[t_{0}, t\right] \subset Z\left[t_{0}, t\right] \times Y\left[t_{0}, t\right]$ be a time space, and $S_{0}\left[t_{0}, t\right] \in S^{\mathcal{S}}\left[t_{0}, t\right]$ an initial state. Then there exists an initial response function $\rho_{0}, \rho_{0}: S_{0}\left[t_{0}, t\right] \times Z\left[t_{0}, t\right] \rightarrow Y\left[t_{0}, t\right]$ which satisfies:

$$
\forall z\left[\mathrm{t}_{0}, t\right] \in Z\left[\mathrm{t}_{0}, t\right], \forall y\left[\mathrm{t}_{0}, t\right] \in Y\left[\mathrm{t}_{0}, t\right], \exists s\left[\mathrm{t}_{0}, t\right] \in S_{0}\left[\mathrm{t}_{0}, t\right] \mid y\left[\mathrm{t}_{0}, t\right]=\rho_{0}\left(s\left[\mathrm{t}_{0}, t\right], z\left[\mathrm{t}_{0}, t\right]\right) .
$$

An initial response function

$$
\rho_{0}: Z\left[t_{0}, t\right] \times S_{0}\left[t_{0}, t\right] \rightarrow Y\left[t_{0}, t\right]
$$


is causal iff

$$
\forall z\left[t_{0}, t\right] \in Z\left[t_{0}, t\right] \wedge \forall s\left[t_{0}, t\right] \in S_{0}\left[t_{0}, t\right], z^{\prime}\left[t_{0}, t\right] \in Z\left[t_{0}, t\right]
$$

with

$$
z\left[t_{0}, t\right]=z^{\prime}\left[t_{0}, t\right], \rho_{0}\left(z\left[t_{0}, t\right], s\left[t_{0}, t\right]\right)=\rho_{0}\left(z^{\prime}\left[t_{0}, t\right], s\left[t_{0}, t\right]\right) .
$$

A system $\Sigma$ is causal iff it has an initial response function.

Causality expresses determinism [24], meaning that each event is the consequence of the set of specific causes that define it. These causes may be unknown or known. Though causality need not be linked with time $T$ explicitly, as a rule if they are known over time their effects are determined. Here we consider a close relationship between time and causal intervals, $\left[t_{0}, t\right] \in T ; t>t_{0}$ where $t_{0}$ represents the starting or current time of a cause, and $t$ the final time of its effect. A causal determination will entail a cause-effect relationship. Direction or orientation is implicit in causality. A causal system $\Sigma$ is oriented when its boundary attributes are separated into causes $Z$ and effects $Y ; \Sigma$ will be expressed as a stimulus-response set of time segments:

$$
\left(z\left[t_{0}, t\right], y\left[t_{0}, t\right]\right) \in \Sigma\left[t_{0}, t\right], z\left[t_{0}, t\right] \in Z\left[t_{0}, t\right], y \in Y\left[t_{0}, t\right] .
$$

An oriented system associates temporal stimulus sequences with temporal response sequences. An oriented causal system $\Sigma$ is functional when stimulus-response relations are expressed as functions that relate time sets of stimuli and time sets of the responses:

$$
\Sigma: Z\left[t_{0}, t\right] \rightarrow Y\left[t_{0}, t\right]
$$

A system $\Sigma$ is uniquely determined when for each stimulus sequence $z\left[t_{0}, t\right] \in Z\left[t_{0}, t\right]$ there corresponds one and only one response sequence, $y\left[t_{0}, t\right] \in Y\left[t_{0}, t\right]$. The role of external observers in defining systems is of singular significance.

Let $H=\left(A, R_{I}\right)$ be the object and relational sets for $A$, an $H$-semiotic system. The objects contain information-based attributes or behaviors associated with the agents $M$ of some ontologic system. For each $a \in A$ and $\forall t \in T, a(t)$ is the value of $a$ in the time $t \in T, a^{t}$ represents behavior before time $t$, and $a_{t}$ denotes behavior after $t[26,27]$. The relations $R_{I}$ are formed by inferential interactions between attributes designated by the observer as processes. Inferential determination is the kind of determination that occurs in the phenomenology of ontologic systems. $\mathrm{H}$-semiotic systems are not anticipatory in the sense that they do not respond at time $t$ to stimuli received after $t$. The two properties of a "unique stimulus-response relation" and "no anticipation" are the essence of a causal relation [23].

Definition 2. (stimulus-response process) We define stimulus-response process to any function

$$
\rho: Z\left[t_{0}, t\right] \times S\left[t_{0}, t\right] \rightarrow Y\left[t_{0}, t\right]
$$

satisfying the following relationship

$$
\left(z\left[t_{0}, t\right], y\left[t_{0}, t\right]\right) \in H\left[t_{0}, t\right] \Rightarrow\left(\exists s\left[t_{0}, t\right] \in S\left[t_{0}, t\right] \mid y\left[t_{0}, t\right]=\rho\left(z\left[t_{0}, t\right], s\left[t_{0}, t\right]\right)\right) .
$$

The function $\rho$ will be called the response process. Given any $H$-system, we have a response processes' family

$$
\mathrm{P}=\left\{\rho \mid \rho: Z\left[t_{0}, t\right] \times S\left[t_{0}, t\right] \rightarrow Y\left[t_{0}, t\right]\right\} .
$$

It is only possible that an $\mathrm{H}$-system would generate more than one response process, corresponding to a given impulse, if $H$ has some information about its future. The function (6) achieves the determinate stimulus-response mapping. 
Definition 3. (state transitions) State transitions are defined by a function

$$
\varphi: Z\left[t_{0}, t\right] \times S\left[t_{0}, t\right] \rightarrow S\left[t_{0}, t\right] .
$$

This function is a transition process. Given any $H$-system, a transition process family of such functions can be formed

$$
\Phi=\left\{\varphi \mid \varphi: Z\left[t_{0}, t\right] \times S\left[t_{0}, t\right] \rightarrow S\left[t_{0}, t\right]\right\} .
$$

Definition 4. (internal transition process) Function $\phi$ is an internal transition process between states

$$
\phi: S\left[t_{0}, t\right] \times S\left[t_{0}, t\right] \rightarrow S\left[t_{0}, t\right] .
$$

Given any $H$-system a family of internal transition processes can be formed

$$
\Theta=\left\{\phi \mid \phi: S\left[t_{0}, t\right] \times S\left[t_{0}, t\right] \rightarrow S\left[t_{0}, t\right]\right\} .
$$

Definition 5. (internal response process) Function $\mu$ will be called an internal response process

$$
\mu: S\left[t_{0}, t\right] \times S\left[t_{0}, t\right] \rightarrow Y\left[t_{0}, t\right] .
$$

Given any $H$-system, a family of internal response processes can be formed

$$
\mathrm{M}=\left\{\mu \mid \mu: S\left[t_{0}, t\right] \times S\left[t_{0}, t\right] \rightarrow Y\left[t_{0}, t\right]\right\} .
$$

Definition 6. (processes space) A processes space $\Pi$ of a $H$-system is the set of process families $P, \Phi, \Theta, M$, denoted as $\Pi=\{\mathrm{P}, \Phi, \Theta, \mathrm{M}\}$, such that for a given time interval $\left[t_{0}, t\right]$ :

$$
\begin{aligned}
& Z\left[t_{0}, t\right] \times S\left[t_{0}, t\right] \stackrel{\mathrm{P}}{\rightarrow} Y\left[t_{0}, t\right] \\
& \downarrow^{\Phi} \quad \uparrow^{\mathrm{M}} \\
& S\left[t_{0}, t\right] \stackrel{\Theta}{\leftarrow} S\left[t_{0}, t\right] \times \quad S\left[t_{0}, t\right]
\end{aligned}
$$

Definition 7. (internal processes space) An internal processes space $\Pi^{*}$ is the subspace of a processes space having as elements both internal responses and transition processes $\Pi^{*}=\{\Theta, M\}$.

$H$-system is open when its process space consists of the whole set of families $P, \Phi, \Theta, M$, and closed when the process space is formed only by $\Theta$; and semi-open when its process space consists only of $\Phi$ or M. Hierarchically, systems, supersystems (environment), and subsystems (components) can all be modeled as $H$-systems. In accordance with Koestler [28], Patten [27,29], Patten and Auble [30,31] and Patten et al. [26] the term "holon" is used to denote systems that are simultaneously part of a greater whole, and a whole made up of lesser parts. A holon faces in two directions at once: Inward and downward toward its own parts, and outward and upward toward the system of which it is a part. Consequently, an H-system is a holon.

\section{Ecosystems, Direct and Indirect Effects}

The definitions of functions (5), (7) and (9) are sufficient for modeling holons ( $H$-systems) that represent physical systems, but do not represent biological systems. The latter have an ability to respond 
to abstractions rather than unmodified environmental stimuli. This depends upon distinguishing coding information at a chemical level from a language level, and by this, forming a basis for distinguishing living and non-living objects.

The role of abstraction used in determining stimulus-response relations can be incorporated explicitly by introducing a modeling function specifying living objects [30]. The holon has in effect produced a many-to-one stimulus-response function by reinterpreting the signals from its environment. That is, the holon has made a model of an effective stimulus $Z$ from an actual physical stimulus $Z^{*}$ based on its state at time $t$ :

$$
\omega: Z\left[t_{0}, t\right] \times S\left[t_{0}, t\right] \rightarrow Z *\left[t_{0}, t\right] .
$$

As Patten [30] has said, the function (14) or the modeling function represents a unique and universal attribute of a living system, namely the ability to abstract from reality, and respond to the abstraction rather than to the absolute reality. In the case of man this abstraction is called knowledge.

Based on the presence or absence of a modeling capability, two classes of $H$-systems can be recognized:

a. Nonliving or abiotic systems $H(\rho, \varphi, \mu)$ where $Z=Z^{*}$. The effective stimulus is whatever the ontological system delivers.

b. Living or biotic systems $H(\rho, \varphi, \mu, \omega)$ or taxa may or may not correspond to bio-systemic categories of the same name.

In accordance with Patten [29], let $H_{i}\left(\rho_{i}, \varphi_{i}, \mu_{i}\right), i=1, \ldots, p$, be abiotic or dead biotic components of an ecosystem and $H_{i}\left(\rho_{i}, \varphi_{i}, \mu_{i}, \omega_{i}\right), i=1, \ldots, q$, be biotic subsystems. The biotope is the set of nonliving subsystems $\left(H_{i}\left(\rho_{i}, \varphi_{i}, \mu_{i}\right), i=1, \ldots, p\right)$. The community is the set of the taxa $\left\{H_{i}\left(\rho_{i}, \varphi_{i}, \mu_{i}, \omega_{i}\right), i=1, \ldots, q\right\}$.

An ecosystem (narrow definition) is the set of all living and nonliving components such as:

$$
\left\{H_{i}\left(\rho_{i}, \varphi_{i}, \mu_{i}\right), H_{j}\left(\rho_{j i}, \varphi_{j}, \mu_{j}, \omega_{j}\right): i=1, \ldots, p ; j=1, \ldots, q ; i+j=n\right\} .
$$

As Patten says in [30], with this background, Hutchinson's [32] hyperspace concept of an ecological niche can be described in system theoretical terms.

An ecosystem is a general system which has many properties that require attention when modeling:

1. Ecosystems are networks of interacting agents-objects and subjects.

2. Ecosystems are hierarchically organised.

3. Ecosystems are collections of environments.

4. Ecosystems are interconnected by a web of of pathways.

5. Ecosystem pathways are complex and intricate.

6. Ecosystem pathways partition constituent environments.

7. Ecosystem agents are mutually interrelated by direct and indirect pathways.

8. Ecosystems tend to equalize energy-matter flows between constituents.

9. Ecosystems tend to derive more than face value from their stimuli.

10. Ecosystems tend to increase distance from the thermodynamic ground.

11. Ecosystems agents are quantitively dominated by indirect interactions.

12. Ecosystems qualitatively transform their agent interactions.

13. Ecosystem determination is predominantly holistic.

14. Ecosystems convey positive utility to their living constituents.

15. Ecosystems are complex adaptative systems.

16. Ecosystems create and proliferate niches for new conditions for life.

17. Ecosystems function as inheritance systems.

18. Ecosystems function as cybernetic systems with distributed control. 
19. Ecosystems function as units of co-evolution.

20. Ecosystems grow expanding the inner space of reality.

A system is an ecosystem (large definition) if it is defined as a living system associated with a nonliving system as is defined by formula (15), among which material, energetic and informational elements must exist and conform to Patten's twenty remarkable properties.

Higashi and Patten [33] consider an ecological system as an open system with $j=1,2, \ldots, n$ steady state compartments, with both constant flows (causes, effects) and standing stocks (causal potentials). Causality within this system, or its physical energy-to-matter relation, is assumed to be conservative.

A cause and effect relation is direct if they are adjacent and the relation is indirect if separated by some distance. In networks, two kinds of distance relationships exist, these relate to time and to route. Generalising the definitions of $H$-systems with respect to routes and times in Patten's theory, the following definitions are obtained:

Let $T$ be a time linearly ordered with its range expressed by $\leq$. Let $\left[t_{0}, t_{f}\right] \subset T$ be a time interval. Let $H\left[t_{0}, t_{f}\right]$ be an $H$-system such as $H\left[t_{0}, t_{f}\right]=\left(M\left[t_{0}, t_{f}\right], R\left[t_{0}, t_{f}\right]\right)$.

\subsection{Direct Effects}

Definition 8. (direct influence with respect to route and time $\left.\left(x r_{D D} y\right)\right) A x\left[t_{0}, t_{f}\right] \in M\left[t_{0}, t_{f}\right]$ variable exerts on variable $y\left[t_{0}, t_{f}\right] \in M\left[t_{0}, t_{f}\right]$ at instant $t \in\left[t_{0}, t_{f}\right]$ a direct influence $x_{D D} y$ with respect to route and time iff:

1. $\left(x\left[t_{0}, t_{f}\right], y\left[t_{0}, t_{f}\right]\right) \in r\left[t_{0}, t_{f}\right], r\left[t_{0}, t_{f}\right] \in R\left[t_{0}, t_{f}\right]$.

2. Variable $x\left[t_{0}, t_{f}\right]$ at instant $t \in\left[t_{0}, t_{f}\right]$ by means of relation $r\left[t_{0}, t_{f}\right] \in R\left[t_{0}, t_{f}\right]$ produces an effect on variable $y\left[t_{0}, t_{f}\right]$ at time $t+\Delta t \in\left[t_{0}, t_{f}\right]$, represented as $r(x(t))=y(t+\Delta t)$.

Definition 9. (direct influence with respect to route and indirect influence with respect to time $\left.\left(x r_{D I} y\right)\right) A$ variable $x\left[t_{0}, t_{f}\right] \in M\left[t_{0}, t_{f}\right]$ exerts on variable $y\left[t_{0}, t_{f}\right] \in M\left[t_{0}, t_{f}\right]$ at instant $t \in\left[t_{0}, t_{f}\right]$ a direct influence with respect to route, and an indirect influence $x r_{D I} y$ with respect to time iff:

1. $\left(x\left[t_{0}, t_{f}\right], y\left[t_{0}, t_{f}\right]\right) \in r\left[t_{0}, t_{f}\right] ; r\left[t_{0}, t_{f}\right] \in R\left[t_{0}, t_{f}\right]$.

2. A variable $x\left[t_{0}, t_{f}\right] \in M\left[t_{0}, t_{f}\right]$ at instant $t \in\left[t_{0}, t_{f}\right]$ by means of relation $r\left[t_{0}, t_{f}\right] \in R\left[t_{0}, t_{f}\right]$ produces an effect on variable $y\left[t_{0}, t_{f}\right] \in M\left[t_{0}, t_{f}\right]$ at time $t+m \Delta t$, where $m$ is a positive integer number, $m>1$ which we represent as $r(x(t))=y(t+m \Delta t)$.

Definition 10. (direct loop with respect to time $\left(x r_{D D} x\right)$ ) $A$ unitary set $A\left[t_{0}, t_{f}\right] \subseteq M\left[t_{0}, t_{f}\right], A\left[t_{0}, t_{f}\right]=$ $\left(x\left[t_{0}, t_{f}\right]\right)$ is a direct loop $x r_{D D} x$ with respect to time at instant $t \in\left[t_{0}, t_{f}\right]$, iff:

1. $\left(x\left[t_{0}, t_{f}\right], x\left[t_{0}, t_{f}\right]\right) \in r\left[t_{0}, t_{f}\right], r\left[t_{0}, t_{f}\right] \in R\left[t_{0}, t_{f}\right]$.

2. Variable $x\left[t_{0}, t_{f}\right] \in M\left[t_{0}, t_{f}\right]$ at instant $t \in\left[t_{0}, t_{f}\right]$, by means of relation $r\left[t_{0}, t_{f}\right] \in R\left[t_{0}, t_{f}\right]$, produces an effect on variable $x$ at time $t+\Delta t$, that is to say $r(x(t))=x(t+\Delta t)$.

Definition 11. (direct circuit or tour with respect to time $\left.\left(x_{1} r_{I D} x_{1}\right)\right) A \operatorname{set} A\left[t_{0}, t_{f}\right] \subseteq M\left[t_{0}, t_{f}\right], A\left[t_{0}, t_{f}\right]=$ $\left\{x_{i}\left[t_{0}, t_{f}\right]\right\}_{i=1}^{n}$ is a direct circuit or tour $x_{1} r_{I D} x_{1}$ with respect to time at instant $t \in\left[t_{0}, t_{f}\right]$, if there exist the relations $r_{1}\left[t_{0}, t_{f}\right], r_{2}\left[t_{0}, t_{f}\right], \ldots, r_{n}\left[t_{0}, t_{f}\right] \in R\left[t_{0}, t_{f}\right]$ where $n$ is a positive integer number, such that:

$$
\begin{aligned}
& \left(x_{1}\left[t_{0}, t_{f}\right], x_{2}\left[t_{0}, t_{f}\right]\right) \in r_{1}\left[t_{0}, t_{f}\right],\left(x_{2}\left[t_{0}, t_{f}\right], x_{3}\left[t_{0}, t_{f}\right]\right) \in r_{2}\left[t_{0}, t_{f}\right], \ldots, \\
& \left(x_{n-1}\left[t_{0}, t_{f}\right], x_{n}\left[t_{0}, t_{f}\right]\right) \in r_{n-1}\left[t_{0}, t_{f}\right],\left(x_{n}\left[t_{0}, t_{f}\right], x_{1}\left[t_{0}, t_{f}\right]\right) \in r_{n}\left[t_{0}, t_{f}\right]
\end{aligned}
$$


and

$$
\begin{aligned}
& r_{1}\left(x_{1}(t)\right)=x_{2}(t+\Delta t), r_{2}\left(x_{2}(t+\Delta t)\right)=x_{3}(t+2 \Delta t), \ldots, \\
& r_{n-1}\left(x_{n-1}(t+(n-2) \Delta t)\right)=x_{n}(t+(n-1) \Delta t), r_{n}\left(x_{n}(t+(n-1) \Delta t)\right)=x_{1}(t+n \Delta t) .
\end{aligned}
$$

\subsection{Indirect Effects}

Definition 12. (indirect influence with respect to route and direct influence with respect to time $\left.\left(x r_{I D} y\right)\right)$ A variable $x\left[t_{0}, t_{f}\right] \in M\left[t_{0}, t_{f}\right]$ exerts on variable $y\left[t_{0}, t_{f}\right] \in M\left[t_{0}, t_{f}\right]$ at instant $t \in\left[t_{0}, t_{f}\right]$, an indirect influence $x r_{I D} y$ with respect to route and a direct influence with respect to time, if there exist the elements $x_{1}\left[t_{0}, t_{f}\right], x_{2}\left[t_{0}, t_{f}\right], \ldots, x_{n}\left[t_{0}, t_{f}\right] \in M\left[t_{0}, t_{f}\right]$ and the relations $r_{1}\left[t_{0}, t_{f}\right], r_{2}\left[t_{0}, t_{f}\right], \ldots, r_{n+1}\left[t_{0}, t_{f}\right] \in R\left[t_{0}, t_{f}\right]$ where $n$ is a positive integer number such that:

$$
\begin{aligned}
& \left(x\left[t_{0}, t_{f}\right], x_{1}\left[t_{0}, t_{f}\right]\right) \in r_{1}\left[t_{0}, t_{f}\right],\left(x_{1}\left[t_{0}, t_{f}\right], x_{2}\left[t_{0}, t_{f}\right]\right) \in r_{2}\left[t_{0}, t_{f}\right], \ldots, \\
& \left(x_{n-1}\left[t_{0}, t_{f}\right], x_{n}\left[t_{0}, t_{f}\right]\right) \in r_{n}\left[t_{0}, t_{f}\right],\left(x_{n}\left[t_{0}, t_{f}\right], y\left[t_{0}, t_{f}\right]\right) \in r_{n+1}\left[t_{0}, t_{f}\right]
\end{aligned}
$$

and

$$
r_{1}(x(t))=x_{1}(t+\Delta t), r_{2}\left(x_{1}(t+\Delta t)\right)=x_{2}(t+2 \Delta t), \ldots, r_{n+1}\left(x_{n}(t+n \Delta t)\right)=y(t+(n+1) \Delta t) .
$$

Definition 13. (indirect influence with respect to both route and time $\left(x r_{I I} y\right)$ ) A variable $x\left[t_{0}, t_{f}\right] \in$ $M\left[t_{0}, t_{f}\right]$ exerts on variable $y\left[t_{0}, t_{f}\right] \in M\left[t_{0}, t_{f}\right]$ at instant $t \in\left[t_{0}, t_{f}\right]$, an indirect influence $x r_{I I} y$ with respect to both route and time, if there exist the elements $x_{1}\left[t_{0}, t_{f}\right], x_{2}\left[t_{0}, t_{f}\right], \ldots, x_{n}\left[t_{0}, t_{f}\right] \in M\left[t_{0}, t_{f}\right]$ and the relations $r_{1}\left[t_{0}, t_{f}\right], r_{2}\left[t_{0}, t_{f}\right], \ldots, r_{n+1}\left[t_{0}, t_{f}\right] \in R\left[t_{0}, t_{f}\right]$ where $n$ is a positive integer number such that:

$$
\begin{gathered}
\left(x\left[t_{0}, t_{f}\right], x_{1}\left[t_{0}, t_{f}\right]\right) \in r_{1}\left[t_{0}, t_{f}\right],\left(x_{1}\left[t_{0}, t_{f}\right], x_{2}\left[t_{0}, t_{f}\right]\right) \in r_{2}\left[t_{0}, t_{f}\right], \ldots \\
,\left(x_{n-1}\left[t_{0}, t_{f}\right], x_{n}\left[t_{0}, t_{f}\right]\right) \in r_{n}\left[t_{0}, t_{f}\right],\left(x_{n}\left[t_{0}, t_{f}\right], y\left[t_{0}, t_{f}\right]\right) \in r_{n+1}\left[t_{0}, t_{f}\right]
\end{gathered}
$$

and

$$
r_{1}(x(t))=x_{1}\left(t+\Delta_{1} t\right), r_{2}\left(x_{1}\left(t+\Delta_{1} t\right)\right)=x_{2}\left(t+\Delta_{2} t\right), \cdots, r_{n+1}\left(x_{n}\left(t+\Delta_{n} t\right)\right)=y\left(t+\Delta_{n+1} t\right),
$$

where $\Delta_{1} t, \Delta_{2} t, \ldots, \Delta_{n+1}$ tare non-consecutive time increments satisfying the condition that $\Delta_{1} t<\Delta_{2} t<\ldots<$ $\Delta_{n+1} t$.

Definition 14. (indirect loop with respect to time $\left(x r_{D I} x\right)$ ) A unitary set $A\left[t_{0}, t_{f}\right] \subseteq M\left[t_{0}, t_{f}\right], A\left[t_{0}, t_{f}\right]=$ $\left(x\left[t_{0}, t_{f}\right]\right)$ is an indirect loop $x_{D I} x$ with respect to time at instant $t \in\left[t_{0}, t_{f}\right]$, iff:

(1) $\left(x\left[t_{0}, t_{f}\right], x\left[t_{0}, t_{f}\right]\right) \in r\left[t_{0}, t_{f}\right], r\left[t_{0}, t_{f}\right] \in R\left[t_{0}, t_{f}\right]$.

(2) Variable $x\left[t_{0}, t_{f}\right] \in M\left[t_{0}, t_{f}\right]$ at instant $t \in\left[t_{0}, t_{f}\right]$, by means of relation $r\left[t_{0}, t_{f}\right] \in R\left[t_{0}, t_{f}\right]$, produces an effect on variable $x$ at time $t+m \Delta t$, where $m$ is a positive integer $m>1$, that is to say $r(x(t))=x(t+m \Delta t)$.

Definition 15. (indirect circuit or tour with respect to time $\left(x_{1} r_{I I} x_{1}\right)$ ) A set $A\left[t_{0}, t_{f}\right] \subseteq$ $M\left[t_{0}, t_{f}\right], A\left[t_{0}, t_{f}\right]=\left\{x_{i}\left[t_{0}, t_{f}\right]\right\}_{i=1}^{n}$ is an indirect circuit $x_{1} r_{I I} x_{1}$ or tour with respect to time at instant $t \in\left[t_{0}, t_{f}\right]$, if there exist the relations $r_{1}\left[t_{0}, t_{f}\right], r_{2}\left[t_{0}, t_{f}\right], \ldots, r_{n}\left[t_{0}, t_{f}\right] \in R\left[t_{0}, t_{f}\right]$ where $n$ is a positive integer number such that:

$$
\begin{aligned}
& \left(x_{1}\left[t_{0}, t_{f}\right], x_{2}\left[t_{0}, t_{f}\right]\right) \in r_{1}\left[t_{0}, t_{f}\right],\left(x_{2}\left[t_{0}, t_{f}\right], x_{3}\left[t_{0}, t_{f}\right]\right) \in r_{2}\left[t_{0}, t_{f}\right], \ldots, \\
& \left(x_{n-1}\left[t_{0}, t_{f}\right], x_{n}\left[t_{0}, t_{f}\right]\right) \in r_{n-1}\left[t_{0}, t_{f}\right],\left(x_{n}\left[t_{0}, t_{f}\right], x_{1}\left[t_{0}, t_{f}\right]\right) \in r_{n}\left[t_{0}, t_{f}\right]
\end{aligned}
$$


and

$$
\begin{aligned}
& r_{1}\left(x_{1}(t)\right)=x_{2}\left(t+\Delta_{1} t\right), r_{2}\left(x_{2}\left(t+\Delta_{1} t\right)\right)=x_{3}\left(t+\Delta_{2} t\right), \ldots, \\
& r_{n-1}\left(x_{n-1}\left(t+\Delta_{n-2} t\right)\right)=x_{n}\left(t+\Delta_{n-1} t\right), r_{n}\left(x_{n}\left(t+\Delta_{n-1} t\right)\right)=x_{1}\left(t+\Delta_{n} t\right),
\end{aligned}
$$

where $\Delta_{1} t, \Delta_{2} t, \cdots, \Delta_{n}$ t are non-consecutive time increments satisfying the condition $\Delta_{1} t<\Delta_{2} t<\cdots<\Delta_{n} t$.

\section{Time Functions}

Let $T$ be a linearly ordered time set. Let $\left[t_{0}, t_{f}\right] \subset T\left[t_{0}, t_{f}\right] \subset T$ and $t_{f}>t_{0}$. Let $H\left[t_{0}, t_{f}\right]$ be an $H$-system such as $H\left[t_{0}, t_{f}\right]=\left(F L\left[t_{0}, t_{f}\right], R L\left[t_{0}, t_{f}\right]\right)$ being $F L$ the first order Lexicon, $S L$ the Stimulus-Lexicon, STL the State-Lexicon, and $R L$ the Response-Lexicon, such as FL $=S L \cup S T L \cup$ $R L$ [6]. There are two classes of structural functions: Time-forward and Time-backward functions are represented as $f$ and $g$, respectively. The left suffix refers to route and the right suffix refers to time. The difference that exists between simple structural functions and structural functions associated with a relationship is the following: The first of them associates all the possible relationships between a system's elements, while the second associates one and only one particular relationship. It will be expressed by a super-index.

\subsection{Time-Forward Functions $f$}

Definition 16. ( $f_{D D}$ structural function) The stimulus-response structural function of diachronically direct influences with respect to route and time is the function $f_{D D}: F L \times T \rightarrow P(M)$, defined as: $\forall \rho\left[t_{0}, t_{f}\right] \in$ $S L\left[t_{0}, t_{f}\right] \cup S T L\left[t_{0}, t_{f}\right]$ and $\forall t \in\left[t_{0}, t_{f}\right] \subset T:$

$$
\begin{gathered}
f_{D D}\left(\rho\left[t_{0}, t_{f}\right], t\right)=\left\{\varphi\left[t_{0}, t_{f}\right] \in S T L\left[t_{0}, t_{f}\right] \cup R L\left[t_{0}, t_{f}\right]\right. \\
\left.\left(\exists r\left[t_{0}, t_{f}\right] \in R_{L}\left[t_{0}, t_{f}\right]\left(\rho\left[t_{0}, t_{f}\right], \varphi\left[t_{0}, t_{f}\right]\right) \in r\left[t_{0}, t_{f}\right]\right) \wedge(r(\rho(t))=\varphi(t+\Delta t))\right\}
\end{gathered}
$$

where $t+\Delta t \in\left[t_{0}, t_{f}\right]$.

In the domain stimulus and state transition, symbols appear that exert a diachronically direct influence with respect to time and route on other variable symbols, and also in the range appear sets of $P(F L)$ made up of response and state transition symbols, which are diachronically influenced directly with respect to time and route by at least one other symbol.

Definition 17. ( $f_{D I}$ structural function) The stimulus-response structural function of diachronically direct influences with respect to route and indirect influences with respect to time is the function $f_{D I}: F L \times T \rightarrow P(F L)$ defined as:

$$
\begin{gathered}
\forall \rho\left[t_{0}, t_{f}\right] \in S L\left[t_{0}, t_{f}\right] \cup S T L\left[t_{0}, t_{f}\right] \text { and } \forall t \in\left[t_{0}, t_{f}\right] \subset T: \\
f_{D I}\left(\rho\left[t_{0}, t_{f}\right], t\right)=\left\{\varphi\left[t_{0}, t_{f}\right] \in S T L\left[t_{0}, t_{f}\right] \cup R L\left[t_{0}, t_{f}\right]\right. \\
\left(\exists r\left[t_{0}, t_{f}\right] \in R_{L}\left[t_{0}, t_{f}\right]\left(\rho\left[t_{0}, t_{f}\right], \varphi\left[t_{0}, t_{f}\right]\right) \in r\left[t_{0}, t_{f}\right]\right) \wedge(r(\rho(t))=\varphi(t+m \Delta t)) \\
\left.m \in \mathbb{N} m>1, t+m \Delta t \in\left[t_{0}, t_{f}\right]\right\}
\end{gathered}
$$

In the domain appear stimulus and state transition symbols which exert a diachronically direct influence in regards to route, and a diachronically indirect influence in regards to time on other symbols. In addition, within the range appear sets of $P(F L)$ made up of response and state transition symbols which are diachronically influenced directly in regards to route, and diachronically indirectly in regards to time, by at least one other symbol. 
Definition 18. ( $f_{I D}$ structural function) The stimulus-response structural function of diachronically indirect influences in regards to route and diachronically direct influences in regards to time is the function $f_{I D}: F L \times T \rightarrow P(F L)$ defined as: $\forall \rho\left[t_{0}, t_{f}\right] \in S L\left[t_{0}, t_{f}\right] \cup S T L\left[t_{0}, t_{f}\right]$ and $\forall t \in\left[t_{0}, t_{f}\right] \subset T:$

$$
\begin{aligned}
f_{I D}\left(\rho\left[t_{0}, t_{f}\right], t\right)=\left\{\varphi\left[t_{0}, t_{f}\right]\right. & \in S T L\left[t_{0}, t_{f}\right] \cup R L\left[t_{0}, t_{f}\right], \exists \rho_{1}\left[t_{0}, t_{f}\right], \rho_{2}\left[t_{0}, t_{f}\right], \ldots, \\
& \rho_{n}\left[t_{0}, t_{f}\right] \in S L\left[t_{0}, t_{f}\right] \cup S T L\left[t_{0}, t_{f}\right], \exists r_{1}\left[t_{0}, t_{f}\right], r_{2}\left[t_{0}, t_{f}\right], \ldots, r_{n+1}\left[t_{0}, t_{f}\right] \in R_{L}\left[t_{0}, t_{f}\right], \\
& \left(\rho\left[t_{0}, t_{f}\right], \rho_{1}\left[t_{0}, t_{f}\right]\right) \in r_{1}\left[t_{0}, t_{f}\right],\left(\rho_{1}\left[t_{0}, t_{f}\right], \rho_{2}\left[t_{0}, t_{f}\right]\right) \in r_{2}\left[t_{0}, t_{f}\right], \ldots \\
& \left(\rho_{n-1}\left[t_{0}, t_{f}\right], \rho_{n}\left[t_{0}, t_{f}\right]\right) \in r_{n}\left[t_{0}, t_{f}\right],\left(\rho_{n}\left[t_{0}, t_{f}\right], \varphi\left[t_{0}, t_{f}\right]\right) \in r_{n+1}\left[t_{0}, t_{f}\right], \wedge \\
& \left(r_{1}(\rho(t))=\rho_{1}(t+\Delta t), r_{2}\left(\rho_{1}(t+\Delta t)\right)=\rho_{2}(t+2 \Delta t), \ldots, r_{n}\left(\rho_{n-1}(t+(n-1) \Delta t)\right)=\rho_{n}(t+n \Delta t),\right. \\
& \left.\left.r_{n+1}\left(\rho_{n}(t+n \Delta t)\right)=\varphi(t+(n+1) \Delta t)\right)\right\},
\end{aligned}
$$

where $t+\Delta t, t+2 \Delta t, \ldots, t+n \Delta t, \ldots t+(n+1) \Delta t \in\left[t_{0}, t_{f}\right]$.

In the domain appear state transition and stimulus symbols which exert a diachronically indirect influence in regards to route, and a diachronically direct influence in regards to time on other symbols. In the range there also appear sets of $P(F L)$ made up of response and state transition symbols which are diachronically influenced indirectly in regards to route, and diachronically directly in regards to time, by at least one other symbol.

Definition 19. ( $f_{I I}$ structural function) The stimulus-response structural function of diachronically indirect influences in regards to both route and time is the function $f_{I I}: F L \times T \rightarrow P(F L)$ defined as: $\forall \rho\left[t_{0}, t_{f}\right] \in$ $S L\left[t_{0}, t_{f}\right] \cup S T L\left[t_{0}, t_{f}\right]$ and $\forall t \in\left[t_{0}, t_{f}\right] \subset T:$

$$
\begin{aligned}
f_{I I}\left(\rho\left[t_{0}, t_{f}\right], t\right)=\left\{\varphi\left[t_{0}, t_{f}\right] \quad\right. & \in S T L\left[t_{0}, t_{f}\right] \cup R L\left[t_{0}, t_{f}\right], \exists \rho_{1}\left[t_{0}, t_{f}\right], \rho_{2}\left[t_{0}, t_{f}\right], \ldots, \\
& \rho_{n}\left[t_{0}, t_{f}\right] \in S L\left[t_{0}, t_{f}\right] \cup S T L\left[t_{0}, t_{f}\right], \exists r_{1}\left[t_{0}, t_{f}\right], r_{2}\left[t_{0}, t_{f}\right], \ldots, r_{n+1}\left[t_{0}, t_{f}\right] \in R_{L}\left[t_{0}, t_{f}\right], \\
& \left(\rho\left[t_{0}, t_{f}\right], \rho_{1}\left[t_{0}, t_{f}\right]\right) \in r_{1}\left[t_{0}, t_{f}\right],\left(\rho_{1}\left[t_{0}, t_{f}\right], \rho_{2}\left[t_{0}, t_{f}\right]\right) \in r_{2}\left[t_{0}, t_{f}\right], \ldots, \\
& \left(\rho_{n-1}\left[t_{0}, t_{f}\right], \rho_{n}\left[t_{0}, t_{f}\right]\right) \in r_{n}\left[t_{0}, t_{f}\right],\left(\rho_{n}\left[t_{0}, t_{f}\right], \varphi\left[t_{0}, t_{f}\right]\right) \in r_{n+1}\left[t_{0}, t_{f}\right], \wedge \\
& \left(r_{1}(\rho(t))=\rho_{1}\left(t+\Delta_{1} t\right), r_{2}\left(\rho_{1}\left(t+\Delta_{1} t\right)\right)=\rho_{2}\left(t+\Delta_{2} t\right), \ldots, r_{n}\left(\rho_{n-1}\left(t+\Delta_{n-1} t\right)\right)=\rho_{n}\left(t+\Delta_{n} t\right),\right. \\
& \left.\left.r_{n+1}\left(\rho_{n}\left(t+\Delta_{n} t\right)\right)=\varphi\left(t+\Delta_{n+1} t\right)\right)\right\}
\end{aligned}
$$

where $\Delta_{1} t, \Delta_{2} t, \Delta_{n} t, \Delta_{n+1} t$ are non-consecutive time increments satisfying the conditions:

$$
\Delta_{1} t<\Delta_{2} t<\Delta_{n} t<\Delta_{n+1} t \text { and } t+\Delta_{1} t, t+\Delta_{2} t, t+\Delta_{n} t, t+\Delta_{n+1} t \in\left[t_{0}, t_{f}\right] .
$$

In the domain appear state transition and stimulus symbols which exert a diachronically indirect influence in regards to both route and time on other symbols, and also in the range appear sets of $P(F L)$ made up of response and state transition symbols which are diachronically influenced indirectly in regards to both time and route by at least one other symbol.

Definition 20. ( $f_{D D}^{r}$ structural function) The stimulus-response structural function of diachronically direct influences in regards to both route and time associated with the linguistic relation $r$ is the function $f^{r} D D: F L \times T \rightarrow P(F L)$ defined as: $\forall \rho\left[t_{0}, t_{f}\right] \in F L\left[t_{0}, t_{f}\right]$ and $\forall t \in\left[t_{0}, t_{f}\right] \subset T:$

$$
f^{r}{ }_{D D}\left(\rho\left[t_{0}, t_{f}\right], t\right)=\left\{\varphi\left[t_{0}, t_{f}\right] \in F L\left[t_{0}, t_{f}\right],\left(\rho\left[t_{0}, t_{f}\right], \varphi\left[t_{0}, t_{f}\right]\right) \in r\left[t_{0}, t_{f}\right] \wedge(r(\rho(t))=\varphi(t+\Delta t))\right\},
$$

where $t+\Delta t \in\left[t_{0}, t_{f}\right]$.

Definition 21. ( $f_{D I}^{r}$ structural function) The stimulus-response structural function of diachronically direct influences in regards to route and diachronically indirect influences in regards to time associated with the linguistic relation $r$, is the function $f^{r} D I: F L \times T \rightarrow P(F L)$ defined as: $\forall \rho\left[t_{0}, t_{f}\right] \in F L\left[t_{0}, t_{f}\right]$ and $\forall t \in\left[t_{0}, t_{f}\right] \subset T$ :

$$
\begin{aligned}
& f^{r} D I\left(\rho\left[t_{0}, t_{f}\right], t\right)=\left\{\varphi\left[t_{0}, t_{f}\right] \in F L\left[t_{0}, t_{f}\right],\left(\rho\left[t_{0}, t_{f}\right], \varphi\left[t_{0}, t_{f}\right]\right) \in r\left[t_{0}, t_{f}\right] \wedge\right. \\
& (r(\rho(t))=\varphi(t+m \Delta t) m \in \mathbb{N} m>1)\},
\end{aligned}
$$


where $t+m \Delta t \in\left[t_{0}, t_{f}\right]$.

\subsection{Time-Backward Functions $g$}

Definition 22. ( $g_{D D}$ structural function) The response-stimulus structural function of diachronically direct influences in regards to both route and time is the function $g_{D D}: F L \times T \rightarrow P(F L)$ defined as: $\forall \rho\left[t_{0}, t_{f}\right] \in$ $S T L\left[t_{0}, t_{f}\right] \cup R L\left[t_{0}, t_{f}\right]$ and $\forall t \in\left[t_{0}, t_{f}\right] \subset T$ :

$$
\begin{aligned}
g_{D D}\left(\rho\left[t_{0}, t_{f}\right], t\right)=\left\{\varphi\left[t_{0}, t_{f}\right]\right. & \in S L\left[t_{0}, t_{f}\right] \cup S T L\left[t_{0}, t_{f}\right], \\
& \left(\exists r\left[t_{0}, t_{f}\right] \in R_{L}\left[t_{0}, t_{f}\right]\left(\varphi\left[t_{0}, t_{f}\right], \rho\left[t_{0}, t_{f}\right]\right) \in r\left[t_{0}, t_{f}\right]\right) \wedge \\
& (r(\varphi(t))=\rho(t+\Delta t))\},
\end{aligned}
$$

where $t+\Delta t \in\left[t_{0}, t_{f}\right]$.

In the domain appear response and state transition symbols which are diachronically influenced directly in regards to time and route by other symbols, and also in the range appear sets of $P(F L)$ that are made up of state transition and stimulus symbols exerting a diachronically direct influence in regards to time and route on at least one other symbol.

Definition 23. ( $g_{D I}$ structural function) The response-stimulus structural function of diachronically direct influences in regards to route and diachronically indirect influences in regards to time is the function $g_{D I}: F L \times T \rightarrow P(F L)$ defined as: $\forall \rho\left[t_{0}, t_{f}\right] \in S T L\left[t_{0}, t_{f}\right] \cup R L\left[t_{0}, t_{f}\right]$ and $\forall t \in\left[t_{0}, t_{f}\right] \subset T:$

$$
\begin{aligned}
g_{D I}\left(\rho\left[t_{0}, t_{f}\right], t\right)=\left\{\varphi\left[t_{0}, t_{f}\right] \quad\right. & \in S L\left[t_{0}, t_{f}\right] \cup S T L\left[t_{0}, t_{f}\right] \\
& \left(\exists r\left[t_{0}, t_{f}\right] \in R_{L}\left[t_{0}, t_{f}\right]\left(\varphi\left[t_{0}, t_{f}\right], \rho\left[t_{0}, t_{f}\right]\right) \in r\left[t_{0}, t_{f}\right]\right) \wedge \\
& (r(\varphi(t))=\rho(t+m \Delta t) m \in \mathbb{N} m>1)\}
\end{aligned}
$$

where $t+m \Delta t \in\left[t_{0}, t_{f}\right]$.

In the domain appear response and state transition symbols that are diachronically influenced directly in regards to route, and diachronically indirectly influenced in regards to time by other symbols. In addition, in the range appear sets of $P(F L)$ made up of state transition and stimulus symbols exerting a diachronically direct influence in regards to route, and exerting a diachronically indirect influence in regards to time, on at least one other symbol.

Definition 24. ( $g_{I D}$ structural function) The response-stimulus structural function of diachronically indirect influences in regards to route and diachronically direct influences in regards to time is the function $g_{I D}: F L \times T \rightarrow P(F L)$ defined as: $\forall \rho\left[t_{0}, t_{f}\right] \in S T L\left[t_{0}, t_{f}\right] \cup R L\left[t_{0}, t_{f}\right]$ and $\forall t \in\left[t_{0}, t_{f}\right] \subset T:$

$$
\begin{aligned}
g_{I D}\left(\rho\left[t_{0}, t_{f}\right], t\right)=\left\{\varphi\left[t_{0}, t_{f}\right]\right. & \in S L\left[t_{0}, t_{f}\right] \cup S T L\left[t_{0}, t_{f}\right], \exists \rho_{1}\left[t_{0}, t_{f}\right], \rho_{2}\left[t_{0}, t_{f}\right], \ldots, \\
& \rho_{n}\left[t_{0}, t_{f}\right] \in S L\left[t_{0}, t_{f}\right] \cup S T L\left[t_{0}, t_{f}\right], \\
& \exists r_{1}\left[t_{0}, t_{f}\right], r_{2}\left[t_{0}, t_{f}\right], \ldots, r_{n+1}\left[t_{0}, t_{f}\right] \in R_{L}\left[t_{0}, t_{f}\right], \\
& \left(\varphi\left[t_{0}, t_{f}\right], \rho_{1}\left[t_{0}, t_{f}\right] \in r_{1}\left[t_{0}, t_{f}\right],\left(\rho_{1}\left[t_{0}, t_{f}\right], \rho_{2}\left[t_{0}, t_{f}\right]\right) \in r_{2}\left[t_{0}, t_{f}\right], \ldots,\right. \\
& \left(\rho_{n-1}\left[t_{0}, t_{f}\right], \rho_{n}\left[t_{0}, t_{f}\right]\right) \in r_{n}\left[t_{0}, t_{f}\right],\left(\rho_{n}\left[t_{0}, t_{f}\right], \rho\left[t_{0}, t_{f}\right]\right) \in r_{n+1}\left[t_{0}, t_{f}\right], \wedge \\
& \left(r_{1}(\varphi(t))=\rho_{1}(t+\Delta t), r_{2}\left(\rho_{1}(t+\Delta t)\right)=\rho_{2}(t+2 \Delta t), \ldots,\right. \\
& \left.\left.r_{n}\left(\rho_{n-1}(t+(n-1) \Delta t)\right)=\rho_{n}(t+n \Delta t), r_{n+1}\left(\rho_{n}(t+n \Delta t)\right)=\rho(t+(n+1) \Delta t)\right)\right\},
\end{aligned}
$$

where $t+\Delta t, t+2 \Delta t, \ldots, t+n \Delta t, \ldots t+(n+1) \Delta t \in\left[t_{0}, t_{f}\right]$

In the domain appear response and state transition symbols that are diachronically influenced indirectly in regards to route and influenced diachronically directly in regards to time by other symbols, 
and also in the range appear sets of $P(F L)$ made up of state transition and stimulus symbols which exert a diachronically indirect influence in regards to route and exert a diachronically direct influence in regards to time on at least one other symbol.

Definition 25. ( $g_{I I}$ structural function) The response-stimulus structural function of diachronically indirect influences in regards to both route and time is the function $g_{I I}: F L \times T \rightarrow P(F L)$ defined as:

$$
\forall \rho\left[t_{0}, t_{f}\right] \in S T L\left[t_{0}, t_{f}\right] \cup R L\left[t_{0}, t_{f}\right]
$$

and $\forall t \in\left[t_{0}, t_{f}\right] \subset T$ :

$$
\begin{aligned}
g_{I I}\left(\rho\left[t_{0}, t_{f}\right], t\right)=\left\{\varphi\left[t_{0}, t_{f}\right] \in S L\left[t_{0}, t_{f}\right] \quad\right. & \cup S T L\left[t_{0}, t_{f}\right], \exists \rho_{1}\left[t_{0}, t_{f}\right], \rho_{2}\left[t_{0}, t_{f}\right], \ldots, \\
& \rho_{n}\left[t_{0}, t_{f}\right] \in S L\left[t_{0}, t_{f}\right] \cup S T L\left[t_{0}, t_{f}\right], \exists r_{1}\left[t_{0}, t_{f}\right], r_{2}\left[t_{0}, t_{f}\right], \ldots, r_{n+1}\left[t_{0}, t_{f}\right] \in R_{L}\left[t_{0}, t_{f}\right], \\
& \left(\varphi\left[t_{0}, t_{f}\right], \rho_{1}\left[t_{0}, t_{f}\right]\right) \in r_{1}\left[t_{0}, t_{f}\right],\left(\rho_{1}\left[t_{0}, t_{f}, \rho_{2}\left[t_{0}, t_{f}\right]\right) \in r_{2}\left[t_{0}, t_{f}\right], \ldots,\right. \\
& \left(\rho_{n-1}\left[t_{0}, t_{f}\right], \rho_{n}\left[t_{0}, t_{f}\right]\right) \in r_{n}\left[t_{0}, t_{f}\right],\left(\rho_{n}\left[t_{0}, t_{f}\right], \rho\left[t_{0}, t_{f}\right]\right) \in r_{n+1}\left[t_{0}, t_{f}\right], \wedge \\
& \left(r_{1}(\varphi(t))=\rho_{1}\left(t+\Delta_{1} t\right), r_{2}\left(\rho_{1}\left(t+\Delta_{1} t\right)\right)=\rho_{2}\left(t+\Delta_{2} t\right), \ldots, r_{n}\left(\rho_{n-1}\left(t+\Delta_{n-1} t\right)\right)=\rho_{n}\left(t+\Delta_{n} t\right),\right. \\
& \left.\left.r_{n+1}\left(\rho_{n}\left(t+\Delta_{n} t\right)\right)=\rho\left(t+\Delta_{n+1} t\right)\right)\right\},
\end{aligned}
$$

where $\Delta_{1} t, \Delta_{2} t, \Delta_{n} t, \Delta_{n+1} t$ are non-consecutive time increments satisfying the conditions: $\Delta_{1} t<\Delta_{2} t<\Delta_{n} t<$ $\Delta_{n+1} t$ and $t+\Delta_{1} t, t+\Delta_{2} t, t+\Delta_{n} t, t+\Delta_{n+1} t \in\left[t_{0}, t_{f}\right]$.

In the domain appear response and state transition symbols that are diachronically influenced indirectly in regards to both time and route by other symbols, and also in the range appear sets of $P(F L)$ made up of state transition and stimulus symbols exerting a diachronically indirect influence in regards to both time and route on at least one other symbol.

Definition 26. ( $g_{D D}^{r}$ structural function) The response-stimulus structural function of diachronically direct influences in regards to both route and time associated with the linguistic relation $r$ is the function $g^{r} D D: F L \times T \rightarrow P(F L)$

defined as: $\forall \rho\left[t_{0}, t_{f}\right] \in F L\left[t_{0}, t_{f}\right]$ and $\forall t \in\left[t_{0}, t_{f}\right] \subset T$ :

$$
g^{r} D D\left(\rho\left[t_{0}, t_{f}\right], t\right)=\left\{\varphi\left[t_{0}, t_{f}\right] \in F L\left[t_{0}, t_{f}\right],\left(\varphi\left[t_{0}, t_{f}\right], \rho\left[t_{0}, t_{f}\right]\right) \in r\left[t_{0}, t_{f}\right] \wedge(r(\varphi(t))=\rho(t+\Delta t))\right\},
$$

where $t+\Delta t \in\left[t_{0}, t_{f}\right]$.

Definition 27. ( $g_{D I}^{r}$ structural function) The response-stimulus structural function of diachronically direct influences in regards to route and diachronically indirect influences in regards to time associated with the linguistic relation $r$ is the function $g^{r} D I: F L \times T \rightarrow P(F L)$ defined as: $\forall \rho\left[t_{0}, t_{f}\right] \in F L\left[t_{0}, t_{f}\right]$ and $\forall t \in\left[t_{0}, t_{f}\right] \subset T$ :

$$
\begin{aligned}
& g^{r} D I\left(\rho\left[t_{0}, t_{f}\right], t\right)=\left\{\varphi\left[t_{0}, t_{f}\right] \in F L\left[t_{0}, t_{f}\right],\left(\varphi\left[t_{0}, t_{f}\right], \rho\left[t_{0}, t_{f}\right]\right) \in r\left[t_{0}, t_{f}\right] \wedge\right. \\
& (r(\varphi(t))=\rho(t+m \Delta t) m \in \mathbb{N} m>1)\},
\end{aligned}
$$

where $t+m \Delta t \in\left[t_{0}, t_{f}\right]$.

From the previous definitions and concepts, four theorems (Theorems 1-4), necessary to understand the structural function (Theorems 1 and 2), which formalizes from a mathematical point of view, the internal structure of the ecosystem. With Theorems 3 and 4 , we describe the structural function as a function of each relation $r$ in particular, from the point of view of the observer or modeler.

Theorem 1. $f_{D D}=\underset{r\left[t_{0}, t_{f}\right] \in R_{L}\left[t_{0}, t_{f}\right]}{U} f_{D D}^{r}$ and similarly: $g_{D D}=\underset{r\left[t_{0}, t_{f}\right] \in R_{L}\left[t_{0}, t_{f}\right]}{\cup} g_{D D}^{r}$. 
Proof: If $\varphi\left[t_{0}, t_{f}\right] \in f_{D D}\left(x\left[t_{0}, t_{f}\right], t\right) \Rightarrow\left(\exists r\left[t_{0}, t_{f}\right] \in R_{L}\left[t_{0}, t_{f}\right]\left(\rho\left[t_{0}, t_{f}\right], \varphi\left[t_{0}, t_{f}\right]\right) \in r\left[t_{0}, t_{f}\right]\right) \wedge r(\rho(t))=$ $\varphi(t+\Delta t)$, where $t, t+\Delta t \in\left[t_{0}, t_{f}\right] \Rightarrow \varphi\left[t_{0}, t_{f}\right] \in f_{D D}^{r}\left(\rho\left[t_{0}, t_{f}\right], t\right) \subseteq \underset{r\left[t_{0}, t_{f}\right] \in R_{L}\left[t_{0}, t_{f}\right]}{\cup} f_{D D}^{r}\left(\rho\left[t_{0}, t_{f}\right], t\right)$.

Otherwise $\varphi\left[t_{0}, t_{f}\right] \in \underset{r\left[t_{0}, t_{f}\right] \in R_{L}\left[t_{0}, t_{f}\right]}{\cup} f_{D D}^{r}\left(\rho\left[t_{0}, t_{f}\right], t\right) \Rightarrow \exists r_{0}\left[t_{0}, t_{f}\right] \in R_{L}\left[t_{0}, t_{f}\right] /$

$\varphi\left[t_{0}, t_{f}\right] \in f_{D D}^{r_{0}}\left(\rho\left[t_{0}, t_{f}\right], t\right) \Rightarrow\left(\rho\left[t_{0}, t_{f}\right], \varphi\left[t_{0}, t_{f}\right]\right) \in r_{0}\left[t_{0}, t_{f}\right] \wedge r_{0}(\rho(t))=\varphi(t+\Delta t) \Rightarrow \varphi\left[t_{0}, t_{f}\right] \in$ $f_{D D}\left(\rho\left[t_{0}, t_{f}\right], t\right)$.

It can be proved similarly that $g_{D D}=\underset{r\left[t_{0}, t_{f}\right] \in R_{L}\left[t_{0}, t_{f}\right]}{U} g_{D D}^{r}$.

Theorem 2. $f_{D I}=\underset{r\left[t_{0}, t_{f}\right] \in R_{L}\left[t_{0}, t_{f}\right]}{\cup} f_{D I}^{r}$ and similarly: $g_{D I}=\underset{r\left[t_{0}, t_{f}\right] \in R_{L}\left[t_{0}, t_{f}\right]}{\cup} g_{D I}^{r}$.

Proof: If $\varphi\left[t_{0}, t_{f}\right] \in f_{D I}\left(x\left[t_{0}, t_{f}\right], t\right) \Rightarrow\left(\exists r\left[t_{0}, t_{f}\right] \in R_{L}\left[t_{0}, t_{f}\right]\left(\rho\left[t_{0}, t_{f}\right], \varphi\left[t_{0}, t_{f}\right]\right) \in r\left[t_{0}, t_{f}\right] \wedge r(\rho(t))=\right.$ $\varphi(t+m \Delta t) m \in \mathbb{N} m>1) \varphi\left[t_{0}, t_{f}\right] \in f_{D I}^{r}\left(\rho\left[t_{0}, t_{f}\right], t\right) \subseteq \underset{r\left[t_{0}, t_{f}\right] \in R_{L}\left[t_{0}, t_{f}\right]}{\cup} f_{D I}^{r}\left(\rho\left[t_{0}, t_{f}\right], t\right)$.

Otherwise $\varphi\left[t_{0}, t_{f}\right] \in \underset{r\left[t_{0}, t_{f}\right] \in R_{L}\left[t_{0}, t_{f}\right]}{\cup} f_{D I}^{r}\left(\rho\left[t_{0}, t_{f}\right], t\right) \Rightarrow \exists r_{0}\left[t_{0}, t_{f}\right] \in R_{L}\left[t_{0}, t_{f}\right] /$

$\varphi\left[t_{0}, t_{f}\right] \in f_{D I}^{r_{0}}\left(\rho\left[t_{0}, t_{f}\right], t\right) \Rightarrow\left(\rho\left[t_{0}, t_{f}\right], \varphi\left[t_{0}, t_{f}\right]\right) \in r_{0}\left[t_{0}, t_{f}\right] \wedge r_{0}(\rho(t))=\varphi(t+m \Delta t) m \in \mathbb{N} m>1$ $\Rightarrow \varphi\left[t_{0}, t_{f}\right] \in f_{D I}\left(x\left[t_{0}, t_{f}\right], t\right)$.

It can be proved similarly that $g_{D I}=\underset{r\left[t_{0}, t_{f}\right] \in R_{L}\left[t_{0}, t_{f}\right]}{\cup} g_{D I}^{r}$.

Theorem 3. $f_{I D}\left(\rho\left[t_{0}, t_{f}\right], t\right) \subseteq \underset{\mu\left[t_{0}, t_{f}\right] \in F L\left[t_{0}, t_{f}\right], t^{\prime}>t_{D D}}{\cup} f_{D}^{r}\left(\mu\left[t_{0}, t_{f}\right], t^{\prime}\right)$.

Proof: If $\varphi\left[t_{0}, t_{f}\right] \in f_{I D}\left(\rho\left[t_{0}, t_{f}\right], t\right) \Rightarrow \exists \rho_{1}\left[t_{0}, t_{f}\right], \rho_{2}\left[t_{0}, t_{f}\right], \ldots, \rho_{n}\left[t_{0}, t_{f}\right] \in S L\left[t_{0}, t_{f}\right] \cup S T L\left[t_{0}, t_{f}\right]$ and $\exists r_{1}\left[t_{0}, t_{f}\right], r_{2}\left[t_{0}, t_{f}\right], \ldots, r_{n+1}\left[t_{0}, t_{f}\right] \in R_{L}\left[t_{0}, t_{f}\right] /$

$\left(\rho\left[t_{0}, t_{f}\right], \rho_{1}\left[t_{0}, t_{f}\right]\right) \in r_{1}\left[t_{0}, t_{f}\right],\left(\rho_{1}\left[t_{0}, t_{f}\right], \rho_{2}\left[t_{0}, t_{f}\right]\right) \in r_{2}\left[t_{0}, t_{f}\right], \ldots,\left(\rho_{n-1}\left[t_{0}, t_{f}\right], \rho_{n}\left[t_{0}, t_{f}\right]\right) \in r_{n}\left[t_{0}, t_{f}\right]$, $\left(\rho_{n}\left[t_{0}, t_{f}\right], \varphi\left[t_{0}, t_{f}\right]\right) \in r_{n+1}\left[t_{0}, t_{f}\right]$

$$
\begin{gathered}
\wedge\left(r_{1}(\rho(t))=\rho_{1}(t+\Delta t), r_{2}\left(\rho_{1}(t+\Delta t)\right)=\rho_{2}(t+2 \Delta t), \ldots, r_{n}\left(\rho_{n-1}(t+(n-1) \Delta t)\right)=\rho_{n}(t+n \Delta t),\right. \\
\left.r_{n+1}\left(\rho_{n}(t+n \Delta t)\right)=\varphi(t+(n+1) \Delta t)\right) .
\end{gathered}
$$

As $\mu\left[t_{0}, t_{f}\right]=\rho_{n}\left[t_{0}, t_{f}\right]$ and $t^{\prime}=t+n \Delta t$ we have $\varphi\left[t_{0}, t_{f}\right] \in f_{D D}\left(\rho\left[t_{0}, t_{f}\right], t^{\prime}\right)$ as we wanted to prove.

Theorem 4. $g_{I D}\left(\rho\left[t_{0}, t_{f}\right], t\right) \subseteq \underset{\mu\left[t_{0}, t_{f}\right] \in F L\left[t_{0}, t_{f}\right], t^{\prime}>t^{\prime}}{\cup} g_{D D}^{r}\left(\mu\left[t_{0}, t_{f}\right], t^{\prime}\right)$

Proof: If $\varphi\left[t_{0}, t_{f}\right] \in g_{I D}\left(\rho\left[t_{0}, t_{f}\right], t\right) \Rightarrow \exists \rho_{1}\left[t_{0}, t_{f}\right], \rho_{2}\left[t_{0}, t_{f}\right], \ldots, \rho_{n}\left[t_{0}, t_{f}\right] \in S L\left[t_{0}, t_{f}\right] \cup S T L\left[t_{0}, t_{f}\right]$ and $\exists r_{1}\left[t_{0}, t_{f}\right], r_{2}\left[t_{0}, t_{f}\right], \ldots, r_{n+1}\left[t_{0}, t_{f}\right] \in R_{L}\left[t_{0}, t_{f}\right] /$

$\left(\varphi\left[t_{0}, t_{f}\right], \rho_{1}\left[t_{0}, t_{f}\right]\right) \in r_{1}\left[t_{0}, t_{f}\right],\left(\rho_{1}\left[t_{0}, t_{f}\right], \rho_{2}\left[t_{0}, t_{f}\right]\right) \in r_{2}\left[t_{0}, t_{f}\right], \ldots,\left(\rho_{n-1}\left[t_{0}, t_{f}\right], \rho_{n}\left[t_{0}, t_{f}\right]\right) \in r_{n}\left[t_{0}, t_{f}\right]$, $\left(\rho_{n}\left[t_{0}, t_{f}\right], \rho\left[t_{0}, t_{f}\right]\right) \in r_{n+1}\left[t_{0}, t_{f}\right]$ $\wedge\left(r_{1}(\rho(t))=\rho_{1}(t+\Delta t), r_{2}\left(\rho_{1}(t+\Delta t)\right)=\rho_{2}(t+2 \Delta t), \ldots, r_{n}\left(\rho_{n-1}(t+(n-1) \Delta t)\right)=\rho_{n}(t+n \Delta t)\right.$, $\left.r_{n+1}\left(\rho_{n}(t+n \Delta t)\right)=\rho(t+(n+1) \Delta t)\right)$. prove.

As $\mu\left[t_{0}, t_{f}\right]=\rho_{1}\left[t_{0}, t_{f}\right]$ and $t^{\prime}=t+n \Delta t$ we have $\varphi\left[t_{0}, t_{f}\right] \in g_{D D}\left(\rho\left[t_{0}, t_{f}\right], t^{\prime}\right)$ as we wanted to

\section{Biotic Relations and Time Functions}

In an ecosystem it is interesting to distinguish among the different connections that are carried out in individuals of one taxon, and those that are carried out among individuals of different taxa. In this 
sense we will formalize as intrataxa and intertaxa the relationships between individuals in a close sense to the program of axiomatization of some early works of J. Woodger in the 1930s [34]. The intrataxa relations settle down among the individuals that form a community. Let $S\left[t_{0}, t_{f}\right]=\left(M\left[t_{0}, t_{f}\right], R\left[t_{0}, t_{f}\right]\right)$ be an ecosystem and $X\left[t_{0}, t_{f}\right], Y\left[t_{0}, t_{f}\right], Z\left[t_{0}, t_{f}\right], \cdots$ be taxa. We represent the individuals of some of these taxa, for example $\left(x_{1}\left[t_{0}, t_{f}\right], x_{2}\left[t_{0}, t_{f}\right], \cdots, x_{n}\left[t_{0}, t_{f}\right]\right) \in X\left[t_{0}, t_{f}\right]$.

Recently, Sasmal and Chattopadhyay [35] have proposed a general model for preypredator with the variables of disease in prey and predator; a model that is subject to weak Allee effects. These Allee effects can destroy or create interior attractors. This allows us to obtain dynamics for the complete model, and so we conclude that the model has either one attractor (that is, only susceptible-infected coexists or susceptible prey survives), or two attractors (bi-stability with only susceptible prey-infected and susceptible prey-predator coexisting or susceptible prey and susceptible prey-predator coexisting).

\subsection{Relation of Symbiosis or Mutualism $\left(r_{1}\right)$}

Biologically the two taxa benefit from the association, and they cannot also live independently one from the other one. Let $X\left[t_{0}, t_{f}\right], Y\left[t_{0}, t_{f}\right] \in M\left[t_{0}, t_{f}\right]$ be two taxa. We have two cases:

\subsection{1. $X$ on $Y\left(X r_{D D}^{+} Y\right)$}

$X\left[t_{0}, t_{f}\right], Y\left[t_{0}, t_{f}\right]$ are in symbiotic relationship iff $X\left[t_{0}, t_{f}\right] \in M\left[t_{0}, t_{f}\right]$ exerts a positive direct influence $X r_{D D}^{+} Y$ in regards to route and time on taxon $Y\left[t_{0}, t_{f}\right] \in M\left[t_{0}, t_{f}\right]$ at instant $t \in\left[t_{0}, t_{f}\right]$, if:

1. If $\left(X\left[t_{0}, t_{f}\right], Y\left[t_{0}, t_{f}\right]\right) \in r_{1}\left[t_{0}, t_{f}\right], r_{1}\left[t_{0}, t_{f}\right] \in R\left[t_{0}, t_{f}\right]$.

2. Taxon $X\left[t_{0}, t_{f}\right]$ at instant $t \in\left[t_{0}, t_{f}\right]$ by means of relation $r_{1}\left[t_{0}, t_{f}\right] \in R\left[t_{0}, t_{f}\right]$ produces a positive effect on taxon $Y\left[t_{0}, t_{f}\right] \in M\left[t_{0}, t_{f}\right]$ at time $t+\Delta t \in\left[t_{0}, t_{f}\right]$, which we represent as $r_{1}(X(t))=$ $Y(t+\Delta t)(+)$

\subsection{2. $Y$ on $X\left(Y r_{D D}^{+} X\right)$}

Taxon $Y\left[t_{0}, t_{f}\right] \in M\left[t_{0}, t_{f}\right]$ exerts a positive direct influence in regards to route and time on taxon $X\left[t_{0}, t_{f}\right] \in M\left[t_{0}, t_{f}\right]$ at instant $t \in\left[t_{0}, t_{f}\right]$, and this we denote $Y r_{D D}^{+} X$ in $t$, if:

1. $\left(Y\left[t_{0}, t_{f}\right], X\left[t_{0}, t_{f}\right]\right) \in r_{1}\left[t_{0}, t_{f}\right], r_{1}\left[t_{0}, t_{f}\right] \in R\left[t_{0}, t_{f}\right]$.

2. Taxon $Y\left[t_{0}, t_{f}\right]$ at instant $t \in\left[t_{0}, t_{f}\right]$ by means of relation $r_{1}\left[t_{0}, t_{f}\right] \in R\left[t_{0}, t_{f}\right]$ produces a positive effect on taxon $X\left[t_{0}, t_{f}\right] \in M\left[t_{0}, t_{f}\right]$ at time $t+\Delta t \in\left[t_{0}, t_{f}\right]$, which we represent as $r_{1}(Y(t))=$ $X(t+\Delta t)(+)$.

\subsection{Relation of Cooperation $\left(r_{1}{ }^{\prime}\right)$}

It is the same as the mutualism relationship or previous symbiosis $r_{1}$, but with the condition that $x$ and $y$ belong to the same population. They allow the carrying out of certain biotic functions that would be impossible or very difficult for isolated individuals, among those that can be mentioned are mutual protection, reproduction, food search, orientation and division of work (e.g., ants). Let $x_{i}\left[t_{0}, t_{f}\right], x_{j}\left[t_{0}, t_{f}\right] \in X\left[t_{0}, t_{f}\right] \in M\left[t_{0}, t_{f}\right]$ be two individuals. We have two cases:

\subsection{1. $x_{i}$ on $x_{j}\left(x_{i} r_{D D}^{+} x_{j}\right)$}

Individuals $x_{i}\left[t_{0}, t_{f}\right], x_{j}\left[t_{0}, t_{f}\right] \in X\left[t_{0}, t_{f}\right] \in M\left[t_{0}, t_{f}\right]$ are in a cooperative relationship $x_{i} r_{D D}^{+} x_{j}$ iff: individual $x_{i}\left[t_{0}, t_{f}\right] \in X\left[t_{0}, t_{f}\right]$ exerts at instant $t \in\left[t_{0}, t_{f}\right]$, a positive direct influence in regards to route and time on individual $x_{j}\left[t_{0}, t_{f}\right] \in X\left[t_{0}, t_{f}\right]$, if:

1. $\left(x_{i}\left[t_{0}, t_{f}\right], x_{j}\left[t_{0}, t_{f}\right]\right) \in r_{1}^{\prime}\left[t_{0}, t_{f}\right], r_{1}^{\prime}\left[t_{0}, t_{f}\right] \in R\left[t_{0}, t_{f}\right]$.

2. Individual $x_{i}\left[t_{0}, t_{f}\right]$ at instant $t \in\left[t_{0}, t_{f}\right]$ by means of relation $r_{1}^{\prime}\left[t_{0}, t_{f}\right] \in R\left[t_{0}, t_{f}\right]$ produces a positive effect on individual $x_{j}\left[t_{0}, t_{f}\right] \in X\left[t_{0}, t_{f}\right]$ at time $t+\Delta t \in\left[t_{0}, t_{f}\right]$, which we represent as $r_{1}^{\prime}\left(x_{i}(t)\right)=x_{j}(t+\Delta t)(+)$. 
5.2.2. $x_{j}$ on $x_{i}\left(x_{j} r_{D D}^{+} x_{i}\right)$

Individual $x_{j}\left[t_{0}, t_{f}\right] \in X\left[t_{0}, t_{f}\right]$ exerts a positive direct influence $x_{j} r_{D D}^{+} x_{i}$ in regards to route and time on individual $x_{i}\left[t_{0}, t_{f}\right] \in X\left[t_{0}, t_{f}\right]$ at instant $t \in\left[t_{0}, t_{f}\right]$, iff:

1. $\left(x_{j}\left[t_{0}, t_{f}\right], x_{i}\left[t_{0}, t_{f}\right]\right) \in r_{1}^{\prime}\left[t_{0}, t_{f}\right], r_{1}^{\prime}\left[t_{0}, t_{f}\right] \in R\left[t_{0}, t_{f}\right]$.

2. Individual $x_{j}\left[t_{0}, t_{f}\right]$ at instant $t \in\left[t_{0}, t_{f}\right]$ by means of relation $r_{1}^{\prime}\left[t_{0}, t_{f}\right] \in R\left[t_{0}, t_{f}\right]$ produces a positive effect on individual $x_{i}\left[t_{0}, t_{f}\right] \in M\left[t_{0}, t_{f}\right]$ at time $t+\Delta t \in\left[t_{0}, t_{f}\right]$, which we represent as $r_{1}^{\prime}\left(x_{j}(t)\right)=x_{i}(t+\Delta t)(+)$.

Structural function associate to mutualism or symbiosis

The function $f_{D D}^{r_{1}}: M\left[t_{0}, t_{f}\right] x T \rightarrow P\left(M\left[t_{0}, t_{f}\right]\right)$ is defined as $\forall X\left[t_{0}, t_{f}\right] \in M\left[t_{0}, t_{f}\right], \forall t \in\left[t_{0}, t_{f}\right] \subset T$,

$$
\begin{aligned}
& f_{D D}^{r_{1}}\left(X\left[t_{0}, t_{f}\right], t\right)=\left\{Y\left[t_{0}, t_{f}\right] \in M\left[t_{0}, t_{f}\right] /\left(X\left[t_{0}, t_{f}\right], Y\left[t_{0}, t_{f}\right] \in r_{1}\left[t_{0}, t_{f}\right] \wedge\right.\right. \\
& \left.r_{1}(X(t))=Y(t+\Delta t)(+) \wedge r_{1}(Y(t))=X(t+\Delta t)(+), \text { where } t+\Delta t \in\left[t_{0}, t_{f}\right]\right\} .
\end{aligned}
$$

And such as

$$
f_{D D}^{r_{1}}\left(X\left[t_{0}, t_{f}\right], t\right)=Y\left[t_{0}, t_{f}\right] \wedge f_{D D}^{r_{1}}\left(Y\left[t_{0}, t_{f}\right], t\right)=X\left[t_{0}, t_{f}\right] .
$$

This function and their inverse function coincide.

\subsection{Relation of Commensalism or Inquilism $\left(r_{2}\right)$}

Biologically, in commensalism, an individual benefits from another who is neither harmed nor benefited by the first one. So one of the individuals comes out the beneficiary, and the other is not harmed. Inquilism is like commensalism, but it is in the domain of location, so that the benefited individual looks for a place to live, or to defend, and food is not relevant. Let $x_{i}\left[t_{0}, t_{f}\right], y_{j}\left[t_{0}, t_{f}\right] \in M\left[t_{0}, t_{f}\right]$ be two individuals. We have two cases:

\subsection{1. $x_{i}$ on $x_{j}\left(x_{i} r_{D D}^{+} y_{j}\right)$}

$x_{i}\left[t_{0}, t_{f}\right], y_{j}\left[t_{0}, t_{f}\right] \in M\left[t_{0}, t_{f}\right]$ are in a commensalist or an inquilist relation if $x_{i}\left[t_{0}, t_{f}\right] \in M\left[t_{0}, t_{f}\right]$ exerts a positive direct influence $x_{i} r_{D D}^{+} y_{j}$ in regards to route and time on $y_{j}\left[t_{0}, t_{f}\right]$ at instant $t \in\left[t_{0}, t_{f}\right]$ iff:

1. $\left(x_{i}\left[t_{0}, t_{f}\right], y_{j}\left[t_{0}, t_{f}\right]\right) \in r_{2}\left[t_{0}, t_{f}\right], r_{2}\left[t_{0}, t_{f}\right] \in R\left[t_{0}, t_{f}\right]$.

2. Individual $x_{i}\left[t_{0}, t_{f}\right]$ at instant $t \in\left[t_{0}, t_{f}\right]$ by means of relation $r_{2}\left[t_{0}, t_{f}\right] \in R\left[t_{0}, t_{f}\right]$ produces a positive effect on individual $y_{j}\left[t_{0}, t_{f}\right]$ at time $t+\Delta t \in\left[t_{0}, t_{f}\right]$, which we represent as $r_{2}\left(x_{i}(t)\right)=$ $y_{j}(t+\Delta t)(+)$.

\subsection{2. $x_{j}$ on $x_{i}\left(y_{j} r_{D D}^{=} x_{j}\right)$}

Individual $y_{j}\left[t_{0}, t_{f}\right] \in M\left[t_{0}, t_{f}\right]$ exerts a neutral direct influence $y_{j} r_{D D}^{=} x_{j}$ in regards to route and time on individual $x_{i}\left[t_{0}, t_{f}\right]$ at instant $t \in\left[t_{0}, t_{f}\right]$, iff:

1. $\quad\left(y_{j}\left[t_{0}, t_{f}\right], x_{i}\left[t_{0}, t_{f}\right]\right) \in r_{2}\left[t_{0}, t_{f}\right], r_{2}\left[t_{0}, t_{f}\right] \in R\left[t_{0}, t_{f}\right]$.

2. Individual $y_{j}\left[t_{0}, t_{f}\right] \in M\left[t_{0}, t_{f}\right]$ at instant $t \in\left[t_{0}, t_{f}\right]$ by means of relation $r_{2}\left[t_{0}, t_{f}\right] \in R\left[t_{0}, t_{f}\right]$ produces a neutral effect on individual $x_{i}\left[t_{0}, t_{f}\right]$ at time $t+\Delta t \in\left[t_{0}, t_{f}\right]$, which we represent as $r_{2}\left(y_{j}(t)\right)=x_{i}(t+\Delta t)(=)$.

Structural function associated to relation of commensalism or inquilism

The function $f_{D D}^{r_{1}}: M\left[t_{0}, t_{f}\right] x T \rightarrow P\left(M\left[t_{0}, t_{f}\right]\right)$ is defined as $\forall\left(x_{i}\left[t_{0}, t_{f}\right], y_{j}\left[t_{0}, t_{f}\right] \in r_{2}\left[t_{0}, t_{f}\right], \forall t \in\right.$ $\left[t_{0}, t_{f}\right] \subset T$,

1. If $x_{i}\left[t_{0}, t_{f}\right]$ is the individual that is neither a beneficiary nor harmed $f_{D D}^{r_{2}}\left(x_{i}\left[t_{0}, t_{f}\right], t\right)=$ $\left\{y_{j}\left[t_{0}, t_{f}\right] \in Y\left[t_{0}, t_{f}\right] / r_{2}\left(x_{i}(t)\right)=y_{j}(t+\Delta t)(+)\right\}$. 
2. If $y_{j}\left[t_{0}, t_{f}\right]$ is the individual that is a beneficiary $f_{D D}^{r_{2}}\left(y_{j}\left[t_{0}, t_{f}\right], t\right)=$ $\left\{x_{i}\left[t_{0}, t_{f}\right] \in X\left[t_{0}, t_{f}\right] / r_{2}\left(y_{j}(t)\right)=x_{i}(t+\Delta t)(=)\right\}$.

For example: the case of fish hindrance, $x_{i}\left[t_{0}, t_{f}\right]$ is the shark with the remora fish $y_{j}\left[t_{0}, t_{f}\right]$ attaching to the shark. Another example are puffins who at times share burrows with rabbits.

\subsection{Relation of Predation, Social Parasitism or Exploitation $\left(r_{3}\right)$}

In an ecosystem, the predation relationship is a reciprocal relationship between two components $X$ and $Y$, that is to say, the relationship of $X$ to $Y$, and the relationship of $Y$ to $X$. It is very important to distinguish these relationships, because they reflect influences that are different from the predation process on both components, where, for example $X$ is the predator and $Y$ is the prey. From the point of view of $X$, the relation of $X$ to $Y$ is a dominant relationship, and from the point of view of $Y$, the relationship of $Y$ to $X$ is a subordinate relationship. The effects of the predation on the predator and on the prey are different. Let $X\left[t_{0}, t_{f}\right], Y\left[t_{0}, t_{f}\right] \in M\left[t_{0}, t_{f}\right]$ be two taxa in predation, social parasitism or exploitation. We have four cases: Two direct, and two indirect effects. The influence of predator on the prey is a direct dominant relationship. In an ecosystem one can have indirect dominant relationships, in which gradations appear. Similarly, we would have the direct subordinated relationship that represents the influence of prey on the predator. Also in an ecosystem, they can have indirect subordinate relationships, in which gradations appear.

\subsubsection{Negative Direct Influence $\left(X r_{D D}^{-} Y\right)$}

$X\left[t_{0}, t_{f}\right] \in M\left[t_{0}, t_{f}\right]$ exerts a negative direct influence $X r_{D D}^{-} Y$ in regards to route and time on taxon $Y\left[t_{0}, t_{f}\right] \in M\left[t_{0}, t_{f}\right]$ at instant $t \in\left[t_{0}, t_{f}\right]$, iff:

1. $\left(X\left[t_{0}, t_{f}\right], Y\left[t_{0}, t_{f}\right]\right) \in r_{3}\left[t_{0}, t_{f}\right], r_{3}\left[t_{0}, t_{f}\right] \in R\left[t_{0}, t_{f}\right]$.

2. Taxon $X\left[t_{0}, t_{f}\right]$ at instant $t \in\left[t_{0}, t_{f}\right]$ by means of relation $r_{3}\left[t_{0}, t_{f}\right] \in R\left[t_{0}, t_{f}\right]$ produces a negative effect on taxon $Y\left[t_{0}, t_{f}\right]$ at time $t+\Delta t \in\left[t_{0}, t_{f}\right]$, which we represent as $r_{3}(X(t))=Y(t+\Delta t)(-)$.

5.4.2. Positive Direct Influence $\left(Y r_{D D}^{+} X\right)$

Taxon $Y\left[t_{0}, t_{f}\right] \in M\left[t_{0}, t_{f}\right]$ exerts a positive direct influence $Y r_{D D}^{+} X$ in regards to route and time on taxon $X\left[t_{0}, t_{f}\right] \in M\left[t_{0}, t_{f}\right]$ at instant $t \in\left[t_{0}, t_{f}\right]$, iff:

1. $\left(Y\left[t_{0}, t_{f}\right], X\left[t_{0}, t_{f}\right]\right) \in r_{3}\left[t_{0}, t_{f}\right], r_{3}\left[t_{0}, t_{f}\right] \in R\left[t_{0}, t_{f}\right]$.

2. Taxon $Y\left[t_{0}, t_{f}\right]$ at instant $t \in\left[t_{0}, t_{f}\right]$ by means of relation $r_{3}\left[t_{0}, t_{f}\right] \in R\left[t_{0}, t_{f}\right]$ produces a positive effect on taxon $X\left[t_{0}, t_{f}\right]$ at time $t+\Delta t \in\left[t_{0}, t_{f}\right]$, which we represent as $r_{3}(Y(t))=X(t+\Delta t)(+)$.

\subsubsection{Negative Indirect Influence $\left(X r_{I D}^{-} Y\right)$}

Taxa $X\left[t_{0}, t_{f}\right], Y\left[t_{0}, t_{f}\right] \in M\left[t_{0}, t_{f}\right]$ are in predation, social parasitism or exploitation if $X\left[t_{0}, t_{f}\right] \in$ $M\left[t_{0}, t_{f}\right]$ exerts a negative indirect influence $X r_{I D}^{-} Y$ in regards to route and direct influence in regards to time on $Y\left[t_{0}, t_{f}\right] \in M\left[t_{0}, t_{f}\right]$ at instant $t \in\left[t_{0}, t_{f}\right]$ iff there exist taxa $X_{1}\left[t_{0}, t_{f}\right], X_{2}\left[t_{0}, t_{f}\right], \cdots, X_{n}\left[t_{0}, t_{f}\right] \in$ $M\left[t_{0}, t_{f}\right]$ where $n$ is a positive integer number such that

$$
\begin{aligned}
& \left(X\left[t_{0}, t_{f}\right], X_{1}\left[t_{0}, t_{f}\right]\right) \in r_{3}\left[t_{0}, t_{f}\right], \cdots,\left(X_{n-1}\left[t_{0}, t_{f}\right], X_{n}\left[t_{0}, t_{f}\right]\right) \in r_{3}\left[t_{0}, t_{f}\right], \\
& \left(X_{n}\left[t_{0}, t_{f}\right], Y\left[t_{0}, t_{f}\right]\right) \in r_{3}\left[t_{0}, t_{f}\right]
\end{aligned}
$$

and

$$
\begin{aligned}
& r_{3}(X(t))=X_{1}(t+\Delta t)(-), r_{3}\left(X_{1}(t+\Delta t)\right)=X_{2}(t+2 \Delta t)(-), \cdots \\
& r_{3}\left(X_{n}(t+n \Delta t)\right)=Y(t+(n+1) \Delta t)(-)
\end{aligned}
$$




\subsubsection{Positive Indirect Influence $\left(Y r_{I D}^{+} X\right)$}

Taxon $Y\left[t_{0}, t_{f}\right] \in M\left[t_{0}, t_{f}\right]$ exerts a positive indirect influence $Y r_{I D}^{+} X$ in regards to route and a direct influence in regards to time on taxon $X\left[t_{0}, t_{f}\right] \in M\left[t_{0}, t_{f}\right]$ at instant $t \in\left[t_{0}, t_{f}\right]$ iff exist taxa $X_{1}\left[t_{0}, t_{f}\right], X_{2}\left[t_{0}, t_{f}\right], \cdots, X_{n}\left[t_{0}, t_{f}\right] \in M\left[t_{0}, t_{f}\right]$ where $n$ is a positive integer number such that:

$$
\begin{aligned}
& \left(Y\left[t_{0}, t_{f}\right], X_{n}\left[t_{0}, t_{f}\right]\right) \in r_{3}\left[t_{0}, t_{f}\right],\left(X_{n}\left[t_{0}, t_{f}\right], X_{n-1}\left[t_{0}, t_{f}\right], \in r_{3}\left[t_{0}, t_{f}\right], \cdots\right. \\
& \left(X_{2}\left[t_{0}, t_{f}\right], X_{1}\left[t_{0}, t_{f}\right]\right) \in r_{3}\left[t_{0}, t_{f}\right],\left(X_{1}\left[t_{0}, t_{f}\right], X\left[t_{0}, t_{f}\right]\right) \in r_{3}\left[t_{0}, t_{f}\right]
\end{aligned}
$$

and

$$
\begin{aligned}
& r_{3}(Y(t))=X_{n}(t+\Delta t)(+), r_{3}\left(X_{n}(t+\Delta t)\right)=X_{n-1}(t+2 \Delta t)(+), \cdots, \\
& r_{3}\left(X_{2}(t+(n-1) \Delta t)\right)=X_{1}(t+n \Delta t)(+), r_{3}\left(X_{1}(t+n \Delta t)\right)=X(t+(n+1) \Delta t)(+) .
\end{aligned}
$$

The parasite is an individual that lives on another (ectoparasite), or inside another (endoparasite), and it feeds, causing damage. The parasite comes out as a beneficiary, and the guest is harmed. In social parasitism or exploitation, the individuals of a population benefit from those of another. On the other hand, in predation there is an extreme parasitism, since there is an individual called a predator that generally hunts and devours another called the prey.

Structural function associated to relation of dominant predation

The function $f_{D D}^{r_{3}}: M\left[t_{0}, t_{f}\right] x T \rightarrow P\left(M\left[t_{0}, t_{f}\right]\right)$ is defined as $\forall\left(X\left[t_{0}, t_{f}\right], Y\left[t_{0}, t_{f}\right] \in r_{3}\left[t_{0}, t_{f}\right]\right.$, $\forall t \in\left[t_{0}, t_{f}\right] \subset T$. If $X\left[t_{0}, t_{f}\right]$ is the predator taxon, then $f_{D D}^{r_{3}}\left(X\left[t_{0}, t_{f}\right], t\right)=$ $\left\{Y\left[t_{0}, t_{f}\right] \in M\left[t_{0}, t_{f}\right] / r_{3}(X(t))=Y(t+\Delta t)(-)\right\}$.

The image of a predator is the set of all its preys.

Structural function associated to relation of subordinate predation

The function $g_{D D}^{r_{3}}: M\left[t_{0}, t_{f}\right] x T \rightarrow P\left(M\left[t_{0}, t_{f}\right]\right)$ is defined as $\forall\left(X\left[t_{0}, t_{f}\right], Y\left[t_{0}, t_{f}\right] \in r_{3}\left[t_{0}, t_{f}\right]\right.$, $\forall t \in\left[t_{0}, t_{f}\right] \subset T$. If $Y\left[t_{0}, t_{f}\right]$ is the prey taxon, then $g_{D D}^{r_{3}}\left(Y\left[t_{0}, t_{f}\right], t\right)=$ $\left\{X\left[t_{0}, t_{f}\right] \in M\left[t_{0}, t_{f}\right] / r_{3}(Y(t))=X(t+\Delta t)(+)\right\}$.

The image of a prey is the set of all its predators. In the case in which taxon $X\left[t_{0}, t_{f}\right]$ is a predator of taxon $Y\left[t_{0}, t_{f}\right]$, and taxon $Y\left[t_{0}, t_{f}\right]$ is a predator of taxon $Z\left[t_{0}, t_{f}\right]$, we will say that taxon $X\left[t_{0}, t_{f}\right]$ also belongs to a structural function associated with the indirect dominant predation relationship, and taxon $Z\left[t_{0}, t_{f}\right]$ also belongs to the structural function associated with the indirect subordinate relationship of predation.

\subsection{Relation of Antibiosis $\left(r_{4}\right)$}

In this relationship a taxon is harmed without the other one obtaining some benefit. Taxa $X\left[t_{0}, t_{f}\right], Y\left[t_{0}, t_{f}\right] \in M\left[t_{0}, t_{f}\right]$ are in a relation of antibiosis iff:

\subsubsection{Negative Direct Influence $\left(\mathrm{Xr}_{D D}^{-} Y\right)$}

Taxon $X\left[t_{0}, t_{f}\right] \in M\left[t_{0}, t_{f}\right]$ exerts a negative direct influence $X r_{D D}^{-} Y$ in regards to route and time on taxon $Y\left[t_{0}, t_{f}\right] \in M\left[t_{0}, t_{f}\right]$ at instant $t \in\left[t_{0}, t_{f}\right]$ iff:

1. $\left(X\left[t_{0}, t_{f}\right], Y\left[t_{0}, t_{f}\right]\right) \in r_{4}\left[t_{0}, t_{f}\right], r_{4}\left[t_{0}, t_{f}\right] \in R\left[t_{0}, t_{f}\right]$.

2. Taxon $X\left[t_{0}, t_{f}\right]$ at instant $t \in\left[t_{0}, t_{f}\right]$ by means of relation $r_{4}\left[t_{0}, t_{f}\right] \in R\left[t_{0}, t_{f}\right]$ produces a negative effect on taxon $Y\left[t_{0}, t_{f}\right]$ at time $t+\Delta t \in\left[t_{0}, t_{f}\right]$ which we represent as $r_{4}(X(t))=Y(t+\Delta t)(-)$.

\subsubsection{Neutral Direct Influence $\left(Y r_{D D}^{=} X\right)$}

Taxon $Y\left[t_{0}, t_{f}\right] \in M\left[t_{0}, t_{f}\right]$ exerts a neutral direct influence $Y r_{D D}^{=} X$ in regards to route and time on taxon $X\left[t_{0}, t_{f}\right] \in M\left[t_{0}, t_{f}\right]$ at instant $t \in\left[t_{0}, t_{f}\right]$ iff:

1. $\left(Y\left[t_{0}, t_{f}\right], X\left[t_{0}, t_{f}\right]\right) \in r_{4}\left[t_{0}, t_{f}\right], r_{4}\left[t_{0}, t_{f}\right] \in R\left[t_{0}, t_{f}\right]$.

2. Taxon $Y\left[t_{0}, t_{f}\right]$ at instant $t \in\left[t_{0}, t_{f}\right]$ by means of relation $r_{4}\left[t_{0}, t_{f}\right] \in R\left[t_{0}, t_{f}\right]$ produces a neutral effect on taxon $X\left[t_{0}, t_{f}\right]$ at time $t+\Delta t \in\left[t_{0}, t_{f}\right]$ which we represent as $r_{4}(Y(t))=X(t+\Delta t)(=)$. 
Structural function associated to relation of antibiosis

The function $f_{D D}^{r_{4}}: M\left[t_{0}, t_{f}\right] x T \rightarrow P\left(M\left[t_{0}, t_{f}\right]\right)$ is defined as $\forall\left(X\left[t_{0}, t_{f}\right], Y\left[t_{0}, t_{f}\right] \in r_{4}\left[t_{0}, t_{f}\right], \forall t \in\right.$ $\left[t_{0}, t_{f}\right] \subset T$,

1. If $X\left[t_{0}, t_{f}\right]$ is the taxon that the beneficiary doesn't leave either partner harmed $f_{D D}^{r_{4}}\left(X\left[t_{0}, t_{f}\right], t\right)=$ $\left\{Y\left[t_{0}, t_{f}\right] \in M\left[t_{0}, t_{f}\right] / r_{4}(X(t))=Y(t+\Delta t)(-)\right\}$.

2. If $Y\left[t_{0}, t_{f}\right]$ is the taxon that comes out harmed $f_{D D}^{r_{4}}\left(Y\left[t_{0}, t_{f}\right], t\right)=$ $\left\{X\left[t_{0}, t_{f}\right] \in M\left[t_{0}, t_{f}\right] / r_{4}(Y(t))=X(t+\Delta t)(=)\right\}$.

\subsection{First Relation of Competition ( $\left.r_{5}\right)$}

It takes place when several organisms, whether or not of the same taxon, use common present resources in a limited quantity, even if they are not in a limited quantity, such that when looking for them, they are harmful to each other. If $X$ and $Y$ are competitors, the relationship " $X$ to $Y$ ", and the relationship " $Y$ to $X$ ", are parallel relationships. The influences of the competition are different on both competitors. In the taxa, there are not a single direct competition, but rather there is also indirect competition (the same also happens with the predation). We will distinguish four competition levels, according to the organisms involved they are: (a) Competitors among the main producers of an ecosystem, (b) animals that compete for the main producers, (c) competition among primary carnivorous animals and, (d) competition among secondary carnivorous animals.

\subsubsection{Parallel Relationship Level 1}

The parallel relationship at level 1 is the competitive relationship among several main producers in ecosystems just as for example, the competitive relationship between grasses and crops. Let $X\left[t_{0}, t_{f}\right], Y\left[t_{0}, t_{f}\right] \in M\left[t_{0}, t_{f}\right]$ be two taxa. We have two cases:

5.6.2. Negative direct influence $X$ to $Y\left(X r_{D D}^{-} Y\right)$

Taxon $X\left[t_{0}, t_{f}\right] \in M\left[t_{0}, t_{f}\right]$ exerts a negative direct influence $X r_{D D}^{-} Y$ in regards to route and time on taxon $Y\left[t_{0}, t_{f}\right] \in M\left[t_{0}, t_{f}\right]$ at instant $t \in\left[t_{0}, t_{f}\right]$, iff:

1. If $\left(X\left[t_{0}, t_{f}\right], Y\left[t_{0}, t_{f}\right]\right) \in r_{5}\left[t_{0}, t_{f}\right], r_{5}\left[t_{0}, t_{f}\right] \in R\left[t_{0}, t_{f}\right]$.

2. Taxon $X\left[t_{0}, t_{f}\right]$ at instant $t \in\left[t_{0}, t_{f}\right]$ by means of relation $r_{5}\left[t_{0}, t_{f}\right] \in R\left[t_{0}, t_{f}\right]$ produces a negative effect on taxon $Y\left[t_{0}, t_{f}\right]$ at time $t+\Delta t \in\left[t_{0}, t_{f}\right]$ which we represent as $r_{5}(X(t))=Y(t+\Delta t)(-)$.

5.6.3. Negative Direct Influence $Y$ to $X\left(Y r_{D D}^{-} X\right)$

Taxon $Y\left[t_{0}, t_{f}\right] \in M\left[t_{0}, t_{f}\right]$ exerts a negative direct influence $Y r_{D D}^{-} X$ in regards to route and time on taxon $X\left[t_{0}, t_{f}\right] \in M\left[t_{0}, t_{f}\right]$ at instant $t \in\left[t_{0}, t_{f}\right]$ iff:

1. $\left(Y\left[t_{0}, t_{f}\right], X\left[t_{0}, t_{f}\right]\right) \in r_{5}\left[t_{0}, t_{f}\right], r_{5}\left[t_{0}, t_{f}\right] \in R\left[t_{0}, t_{f}\right]$.

2. Taxon $Y\left[t_{0}, t_{f}\right]$ at instant $t \in\left[t_{0}, t_{f}\right]$ by means of relation $r_{5}\left[t_{0}, t_{f}\right] \in R\left[t_{0}, t_{f}\right]$ produces a negative effect on taxon $X\left[t_{0}, t_{f}\right]$ at time $t+\Delta t \in\left[t_{0}, t_{f}\right]$ which we represent as $r_{5}(Y(t))=X(t+\Delta t)(-)$.

\subsubsection{Parallel Relationship Level 2}

This is the competitive relationship among phytophagous animals for example, just like the relationship among different phytophagous insects. Taxa $X\left[t_{0}, t_{f}\right], Y\left[t_{0}, t_{f}\right] \in M\left[t_{0}, t_{f}\right]$ are in a parallel 
relationship at level 2 if, in the previous definition, we add the existence of a taxon that is a main producer of the ecosystem (for example grass or other harvests), such that:

$$
\begin{aligned}
& r_{3}(X(t))=Z(t+\Delta t)(-) \\
& r_{3}(Y(t))=Z(t+\Delta t)(-) \\
& r_{3}(Z(t))=X(t+\Delta t)(+) \\
& r_{3}(Z(t))=Y(t+\Delta t)(+)
\end{aligned}
$$

that is to say, $X$ and $Y$ compete to be the main producers.

\subsubsection{Parallel Relationship Level 3}

The parallel relationship at level 3 is the competitive relation among primary carnivorous animals, just like for example, the relationship among primary carnivorous insects.

Taxa $X\left[t_{0}, t_{f}\right], Y\left[t_{0}, t_{f}\right] \in M\left[t_{0}, t_{f}\right]$ are in parallel relationship at level 3 if we substitute taxon $Z\left[t_{0}, t_{f}\right]$ from the previous definition for a taxon that is a herbivore in the ecosystem (that is to say, $X$ and $Y$ compete to be the main herbivore).

\subsubsection{Parallel Relationship Level 4}

The parallel relationship at level 4 is the competitive relationship among secondary carnivorous animals for example, the leopard and the hyena compete for the zebra.

Taxa $X\left[t_{0}, t_{f}\right], Y\left[t_{0}, t_{f}\right] \in M\left[t_{0}, t_{f}\right]$ are in parallel relationship level 4 if we substitute a parallel taxon from the previous definition for a taxon that is a primary carnivorous animal in the ecosystem (that is to say, $X$ and $Y$ compete to be the main carnivore).

\subsection{Second Relation of Competition $\left(r_{5}^{\prime}\right)$}

This is defined in the same manner as the relationship of the previous competition $\mathrm{r}_{5}$. Interaction among individuals of the same taxon is caused by the common necessity of a limited resource that reduces the survival, growth and/or reproduction of individual competitors. It is necessary to notice that if the competition can be unfavorable for the population's individuals, it can favor the population considered globally; on the other hand, since there will be more capable individuals, and these will survive, then they will contribute to following generations. Individuals $x_{i}\left[t_{0}, t_{f}\right], x_{j}\left[t_{0}, t_{f}\right] \in X\left[t_{0}, t_{f}\right] \in$ $M\left[t_{0}, t_{f}\right]$ are in competition in the following cases:

\subsubsection{Negative Direct Influence in Regards to Route and Time $x_{i}$ to $x_{j}\left(x_{i} r_{D D}^{-} x_{j}\right)$}

Individual $x_{i}\left[t_{0}, t_{f}\right] \in X\left[t_{0}, t_{f}\right]$ exerts a negative direct influence $x_{i} r_{D D}^{-} x_{j}$ in regards to route and time on individual $x_{j}\left[t_{0}, t_{f}\right] \in X\left[t_{0}, t_{f}\right]$ at instant $t \in\left[t_{0}, t_{f}\right]$, if:

1. $\left(x_{i}\left[t_{0}, t_{f}\right], x_{j}\left[t_{0}, t_{f}\right]\right) \in r_{5}^{\prime}\left[t_{0}, t_{f}\right], r_{5}^{\prime}\left[t_{0}, t_{f}\right] \in R\left[t_{0}, t_{f}\right]$.

2. Individual $x_{i}\left[t_{0}, t_{f}\right]$ at instant $t \in\left[t_{0}, t_{f}\right]$ by means of relation $r_{5}^{\prime}\left[t_{0}, t_{f}\right] \in R\left[t_{0}, t_{f}\right]$ produces a negative effect on individual $x_{j}\left[t_{0}, t_{f}\right] \in X\left[t_{0}, t_{f}\right]$ at time $t+\Delta t \in\left[t_{0}, t_{f}\right]$, which we represent as $r_{5}^{\prime}\left(x_{i}(t)\right)=x_{j}(t+\Delta t)(-)$.

5.7.2. Negative Direct Influence in Regards to Route and Time $x_{j}$ to $x_{i}\left(x_{j} r_{D D}^{-} x_{i}\right)$

Individual $x_{j}\left[t_{0}, t_{f}\right] \in X\left[t_{0}, t_{f}\right]$ exerts a negative direct influence $x_{j} r_{D D}^{-} x_{i}$ in regards to route and time on individual $x_{i}\left[t_{0}, t_{f}\right] \in X\left[t_{0}, t_{f}\right]$ at instant $t \in\left[t_{0}, t_{f}\right]$, if:

1. $\left(x_{j}\left[t_{0}, t_{f}\right], x_{i}\left[t_{0}, t_{f}\right]\right) \in r_{5}^{\prime}\left[t_{0}, t_{f}\right], r_{5}^{\prime}\left[t_{0}, t_{f}\right] \in R\left[t_{0}, t_{f}\right]$.

2. Individual $x_{j}\left[t_{0}, t_{f}\right]$ at instant $t \in\left[t_{0}, t_{f}\right]$ by means of relation $r_{5}^{\prime}\left[t_{0}, t_{f}\right] \in R\left[t_{0}, t_{f}\right]$ produces a negative effect on individual $x_{i}\left[t_{0}, t_{f}\right] \in M\left[t_{0}, t_{f}\right]$ at time $t+\Delta t \in\left[t_{0}, t_{f}\right]$, which we represent as $r_{5}^{\prime}\left(x_{j}(t)\right)=x_{i}(t+\Delta t)(-)$. 
Structural function associated to relation of competition

The function $f_{D D}^{r_{5}}: M\left[t_{0}, t_{f}\right] x T \rightarrow P\left(M\left[t_{0}, t_{f}\right]\right)$ is defined as:

$$
\begin{gathered}
\forall\left(X\left[t_{0}, t_{f}\right], Y\left[t_{0}, t_{f}\right]\right) \in r_{5}\left[t_{0}, t_{f}\right] \forall t \in\left[t_{0}, t_{f}\right] \subset T \\
f_{D D}^{r_{5}}\left(X\left[t_{0}, t_{f}\right], t\right)=\left\{Y\left[t_{0}, t_{f}\right] \in M\left[t_{0}, t_{f}\right] / r_{5}(X(t))=Y(t+\Delta t)(-) \wedge r_{5}(Y(t))=X(t+\Delta t)\right\} .
\end{gathered}
$$

The image of a taxon will be all its taxa competitors.

\subsection{Neutral Relation $\left(r_{6}\right)$}

In this relationship, none comes out as the beneficiary, and neither is harmed. When two taxa in an ecosystem are not in a relationship, we will say that they are related by means of a neutral relationship. In an ecosystem, all the taxa would act as state or internal variables, since in the case where two taxa do not exchange anything, they have a neutral relationship.

Consequence: All the taxa of an ecosystem will be independent.

\section{Conclusions}

In spite of the fact that in domains such as ecosystems, the relations between different variables can be measured, and the various direct and indirect effects compared, for example with some biotic relations, no such development has occurred in the wider context of General Systems Theory.

The question of quantifying the relations between the variables (objects) of a system remains to be resolved, and more generally, quantifying the relations between partial systems, various subsystems, or multilevel systems. The present work is a first step, following Patten's Theory of Environment, to formalise the basic concepts for variables, and to analyse the theoretical properties of direct and indirect influences from the perspective of the variables and the structure of the system.

We take the following position: We do not know if reality itself has a systemic structure. Even more, different structures may correspond to a determined system, or different systems can be equally supported by experience. In such cases, it is possible that reality excludes all structures except one. However, at the same time it is possible that various structures will reflect certain aspects of reality. So, we can keep in mind that all thought will imply a simplification, and that in such a simplification a structure can in some ways reflect aspects of reality. However, if we cannot safely say that a structure is reality, or a part of reality, or an approximate copy of reality, this does not mean that the structures are completely disconnected from reality. If the corresponding appropriate systems are confirmed by experience, then the structures are modeling or simulating experience, and possibly future experiences, at least to a certain degree of approximation. In this way, reason and experience together leads us in the pre-selection of structures, and helps us construct structural models gradually through stages, and gives us reasons for rejecting certain structures in favor of others. However, nothing has been said that justifies talking about natural structures (independent of the theorizing subject) that can be discovered in things. In other words, there is a natural mental tendency to build structures, or to prefer certain structures to others, that belongs to the field of psychology, and does not fall within the objectives of this paper. The application of structural functions to specific cases, especially ecological ones, is beyond the scope of this paper. Although it would be possible to study an ecosystem that takes as units the population or the biomass, by means of the functions $f$ and $g$, each with a particular relationship (symbiosis, predation, etc.) and symbolized through structural features associated with the relationship.

Author Contributions: Conceptualization, J.-L.U.-D., J.-A.N.-S. and M.L.-C.; methodology, J.-L.U.-D., J.-A.N.-S. and M.L.-C.; formal analysis, J.-L.U.-D., J.-A.N.-S. and M.L.-C.; investigation, J.-L.U.-D., J.-A.N.-S. and M.L.-C.; writing-original draft preparation, J.-L.U.-D., J.-A.N.-S., M.L.-C., H.G. and K.A.; writing-review and editing, J.-A.N.-S., H.G. and K.A.-S.; visualization, J.-L.U.-D., J.-A.N.-S., M.L.-C., H.G. and K.A.-S.; supervision, J.-L.U.-D., J.-A.N.-S. and M.L.-C.; project administration, J.-L.U.-D., J.-A.N.-S. and M.L.-C.

Funding: This research received no external funding. 
Conflicts of Interest: The authors declare no conflict of interest.

\section{References}

1. Proctor, R.W.; Kim-Phuong, L.V. Stimulus-Response Compatibility Principles: Data, Theory, and Application, 1st ed.; CRC Press: Boca Ratón, FL, USA, 2006.

2. Usó-Doménech, J.L.; Nescolarde-Selva, J.A.; Lloret-Climent, M. Behaviours, processes and probabilistic environmental functions in h-open systems. Am. J. Syst. Softw. 2014, 2, 65-71.

3. Villacampa, Y.; Usó-Domènech, J. Mathematical models of complex structural systems: A linguistic vision. Int. J. Gen. Syst. 1999, 28, 37-52. [CrossRef]

4. Agazzi, E. Some Philosophical Implications of Gödel's Theorem. Travaux de Logique 1992, 7, 129-159.

5. Hume, D. Enquiry Concerning the Human Understanding; Clarendon Press: Oxford, UK, 1748; Available online: http://www.davidhume.org/texts/ehu.html (accessed on 1 December 2018).

6. Lloret-Climent, M.; Usó-Domènech, J.; Patten, B.; Vives-Maciá, F. Causality in H-semiotic systems of ecosystems: Routes and tours. Int. J. Gen. Syst. 2002, 31, 119-130. [CrossRef]

7. Usó-Domènech, J.; Mateu, J.; Patten, B. Mathematical approach to the concept of environment: Open systems and processes. Int. J. Gen. Syst. 2002, 31, 213-223. [CrossRef]

8. Usó-Domènech, J.L.; Lloret-Climent, M.; Vives-Macià, F.; Patten, B.C.; Sastre-Vázquez, P. Epistemological and mathematical considerations on the structure of h-semiotic systems. Cybern. Syst. 2002, 33, 507-535. [CrossRef]

9. $\quad$ Estes, J.A.; Brashares, J.S.; Power, M.E. Predicting and Detecting Reciprocity between Indirect Ecological Interactions and Evolution. Am. Nat. 2013, 181, S76-S99. [CrossRef]

10. Moussaoui, A.; Auger, P.; Roche, B. Effect of Hawk-Dove Game on the Dynamics of Two Competing Species. Acta Biotheor. 2014, 62, 385-404. [CrossRef]

11. Flores, J.C. Competitive Exclusion and Axiomatic Set-Theory: De Morgan's Laws, Ecological Virtual Processes, Symmetries and Frozen Diversity. Acta Biotheor. 2016, 64, 85-98. [CrossRef]

12. Lin, Y.; Ma, Y.-H. Remarks on analogy between systems. Int. J. Gen. Syst. 1987, 13, 135-141. [CrossRef]

13. Rosen, R. Dynamical System Theory in Biology, 1st ed.; Wiley-Interscience: New York, NY, USA, 1970.

14. Rosen, R. Some system theoretical problems in biology. In The Relevance of General Systems Theory; Laszlo, E., Ed.; George Braziller: New York, NY, USA, 1972.

15. Rosen, R. Old trends and new trends in general systems researcht. Int. J. Gen. Syst. 1979, 5, 173-184. [CrossRef]

16. Lloret-Climent, M.; Villacampa-Esteve, Y.; Usó-Doménech, J.L. System Linkage: Structural Functions and Hierarchies. Cybern. Syst. Int. J. 1998, 29, 35-45. [CrossRef]

17. Nescolarde-Selva, J.; Vives-Maciá, F.; Usó-Domènech, J.; Berend, D.; Nescolarde-Selva, J.; Vives-Maciá, F.; Usó-Doménech, J. An introduction to alysidal algebra (I). Kybernetes 2012, 41, 21-34. [CrossRef]

18. Nescolarde-Selva, J.; Vives-Maciá, F.; Usó-Doménech, J.; Berend, D. An introduction to alysidal algebra (II). Kybernetes 2012, 41, 780-793. [CrossRef]

19. Nescolarde-Selva, J.A.; Usó-Doménech, J.-L. Semiotic Vision of Ideologies. Found. Sci. 2013, 19, $263-282$. [CrossRef]

20. Nescolarde-Selva, J.; Usó-Domènech, J.; Nescolarde-Selva, J.; Usó-Doménech, J. An introduction to alysidal algebra (III). Kybernetes 2012, 41, 1638-1649. [CrossRef]

21. Usó-Doménech, J.L.; Nescolarde-Selva, J. Mathematic and Semiotic Theory of Ideological Systems; LAP LAMBERT Academic Publishing: Saarbrücken, Germany, 2012.

22. Patten, B.C. Holoecology: The Unification of Nature by Network Indirect Effects; Complexity in Ecological Systems Series; Columbia University Press: New York, NY, USA, 2003.

23. Zadeh, L.A.; Desoer, C.A. Linear System Theory. The State Space Approach; McGraw-Hill: New York, NY, USA, 1963.

24. Mesarovic, M.D.; Takahara, Y. General Systems Theory: Mathematical Foundations; Academic Press: New York, NY, USA, 1975.

25. Mesarovic, M.D.; Takahara, Y. Abstract Systems Theory. In Lecture notes in Control and Information Science; Thomas, M., Wyner, A., Eds.; Springer: Berlin, Germany, 1989. 
26. Patten, B.C.; Bosserman, R.W.; Finn, J.T.; Cale, W.G. Propagation of Cause in Ecosystems. In Systems Analysis and Simulation in Ecology; Patten, B., Ed.; Academic Press: New York, NY, USA, 1976; pp. 457-579.

27. Patten, B.C. Systems Approach to the concept of Environment. Ohio J. Sci. 1978, 78, 206-222.

28. Koestler, A. The Ghost in the Machine; MacMillan: New York, NY, USA, 1967.

29. Patten, B.C. Environs: Relativistic Elementary Particles for Ecology. Am. Nat. 1982, 119, 179-219. [CrossRef]

30. Patten, B.C.; Auble, G.T. Systems approach to the concept of niche. Synthese 1980, 43, 155-181. [CrossRef]

31. Patten, B.C.; Auble, G.T. System Theory of the Ecological Niche. Am. Nat. 1981, 117, 893-922. [CrossRef]

32. Hutchinson, G.E. Concluding Remarks. Cold Harb. Symp. Quant. Boil. 1957, 22, 415-427. [CrossRef]

33. Higashi, M.; Patten, B.C. Dominance of Indirect Causality in Ecosystems. Am. Nat. 1989, 133, $288-302$. [CrossRef]

34. Woodger, J.H. The Axiomatic Method in Biology; Cambridge University Press: Cambridge, UK, 1937.

35. Sasmal, S.K.; Chattopadhyay, J. An eco-epidemiological system with infected prey and predator subject to the weak Allee effect. Math. Biosci. 2013, 246, 260-271. [CrossRef] [PubMed]

C 2019 by the authors. Licensee MDPI, Basel, Switzerland. This article is an open access article distributed under the terms and conditions of the Creative Commons Attribution (CC BY) license (http://creativecommons.org/licenses/by/4.0/). 